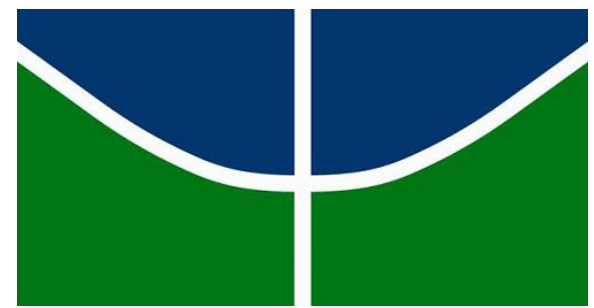

Universidade de Brasília

Faculdade de Tecnologia

Departamento de Engenharia Florestal

FABIULA RIBEIRO BATISTA

\title{
Decomposição de Serapilheira em área do cerrado sentido restrito e plantio de eucalipto no Distrito Federal
}



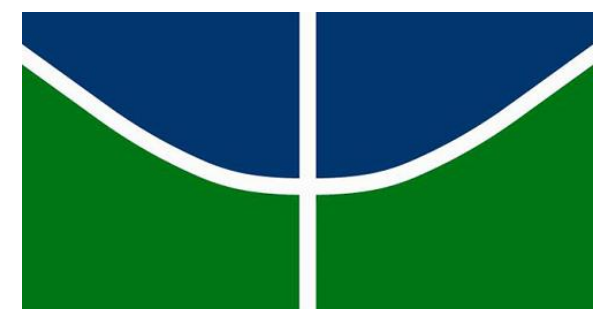

Universidade de Brasília - UnB

Faculdade de Tecnologia - FT

Departamento de Engenharia Florestal

\title{
Decomposição de Serapilheira em área do cerrado sentido restrito e plantio de eucalipto no Distrito Federal
}

\author{
Aluna: FABIULA RIBEIRO BATISTA \\ Orientador: Prof. Dr. Reginaldo Sérgio Pereira \\ Coorientadora: Dr. ${ }^{a}$ Fabrícia Conceição Menez Mota
}

\begin{abstract}
Trabalho de conclusão de curso apresentado ao Departamento de Engenharia Florestal da Universidade de Brasília, como parte das exigências para obtenção do título de Engenheira Florestal.
\end{abstract}

Brasília-DF, 07 de dezembro de 2017 


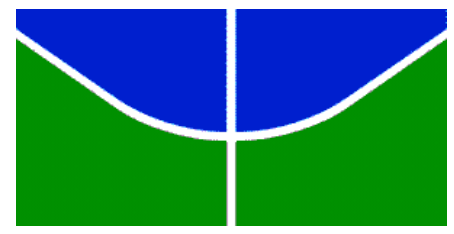

Universidade de Brasília

Faculdade de Tecnologia

Departamento de Engenharia Florestal

\section{Decomposição de Serapilheira em área do cerrado sentido restrito e plantio de eucalipto no Distrito Federal}

Estudante: FABIULA RIBEIRO BATISTA

Matrícula: 11/0116461

Orientador: Prof. Dr. Reginaldo Sérgio Pereira

Menção:

Prof. Dr. Reginaldo Sérgio Pereira

Universidade de Brasília - UnB

Departamento de Engenharia Florestal

Orientador

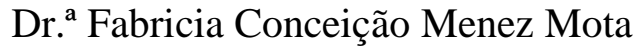

Coorientadora

Membro da Banca

Doutorando Marco Bruno Xavier Valadão

PPGCF/EFL/UnB

Membro da Banca

Brasília-DF, dezembro de 2017 


\section{AGRADECIMENTOS}

Agradeço primeiramente a Deus, por me manter firme com os meus objetivos e nunca perder a fé, mesmo diante de grandes problemas, me mostrando que tudo é possível para aquele que crer.

Aos meus pais Sérgio Ribeiro e Carmelita Pereira que sempre foram é os meus maiores exemplos e incentivadores. Por sempre fazerem o impossível para proporcionar a mim e meu irmão as melhores coisas. Sem vocês esse sonho não poderia ter se tornado realidade. Amo vocês.

Ao meu irmão, Wasington Ribeiro, por sempre está ao meu lado, por me apoiar e ajudar em tudo. Com você aprendi o verdadeiro significado da palavra irmão. Amo muito você.

A todos os meus familiares que perto ou longe sempre torceram pela minha felicidade. Em particular a minha tia Luciana, você me salvou. Ao meu amigo Willian por sempre me incentivar e vê o lado positivo das coisas.

Ao meu orientador Dr. Reginaldo Sérgio Pereira, pela oportunidade. A Dr. ${ }^{a}$ Fabrícia Conceição Menez Mota, que além de minha coorientadora uma grande amiga. Obrigada pela imensa ajuda.

A todos os professores do departamento, pelas experiências e aprendizados. Em especial ao Professor Éder.

Ao meu amigo Marco Bruno Xavier Valadão por toda atenção, apoio e paciência na colaboração das análises estatísticas. Sem você não teria conseguido, obrigado.

Aos meus amigos de graduação Bruno, Quércia, Mayara, Lorrany, Alexandre, Gabi, Fernanda, Ana Clara, Patrícia, Bruna, Eduardo, Maria Helena e Bianca. Em especial ao Marcos, pela imensa ajuda. A você meu muito obrigado. E claro a Priscilla, minha maior companheira, que nesses anos de graduação me ajudou e sempre esteve ao meu lado, me ajudando e me fazendo acreditar que tudo daria certo.

Aos Funcionários da Fazenda Água Limpa, sr. Sebastião, Geraldo, Mauro, Zico, por toda ajuda na coleta de dados em campo.

E a todos que torceram e contribuíram para que esse trabalho fosse realizado. 


\section{RESUMO}

O objetivo deste trabalho foi avaliar a taxa de perda de massa foliar através das variáveis climáticas em duas vegetações: cerrado típico e em plantio de eucalipto híbrido clonal (urophylla $x$ grandis), em função do método de sacolas de decomposição (litterbags). O decaimento foliar é observado quando há perca da massa do folhedo. Com duas estações bem definidas, a estação chuvosa tem início em outubro e estende-se até março e estação seca de abril até setembro. O experimento foi realizado na Reserva Ecológica e Experimental da Universidade de Brasília, Fazenda água Limpa (FAL). Nessa pesquisa também foram utilizados dados obtidos da estação meteorológica da FAL. Nas duas áreas fez-se o procedimento de instalação de parcelas para serem monitoradas durante o período da pesquisa. Para início do experimento foram realizadas coletadas das folhas recém caídas em agosto de 2015. A partir da coleta, as folhas foram alocadas em bolsas feitas de nylon, denominadas de sacolas de decomposição, que continham em cada amostra $20 \mathrm{~g}$ de folhas que foram realocadas novamente nas áreas de cerrado e eucalipto, para posterior análise da perda de biomassa. A avaliação da decomposição foi feita mensalmente, no período de outubro de 2015 a setembro de 2016. Os resultados indicaram que foi similar o porcentual de perda de massa em ambas as vegetações. Com 12 meses de análise, o cerrado e o eucalipto ainda tinha mais de $60 \%$ da sua massa inicial. Com uma alta relação $\mathrm{C} / \mathrm{N}$ para as duas vegetações.

Palavra Chave: Ciclagem de nutrientes, eucalipto, cerrado, sacolas de decomposição. 


\begin{abstract}
The objective of this work was to evaluate the rate of leaf mass loss through climatic variables in two vegetations: typical cerrado and clonal hybrid eucalyptus (urophylla $x$ grandis), as a function of the litterbags method. Foliar decay is observed when the leaf mass is lost. With two well-defined seasons, the rainy season starts in October and runs through March and the dry season from April to September. The experiment was carried out at the Ecological and Experimental Reserve of the University of Brasilia, Fazenda Água Limpa (FAL). In this research were also used data obtained from the FAL meteorological station. In both areas, the plots were installed to be monitored during the period of the survey. For the beginning of the experiment were collected from the newly fallen leaves in August 2015. From the collection, the leaves were allocated in bags made of nylon, called bags of decomposition, which contained in each sample $20 \mathrm{~g}$ of leaves that were relocated again in the areas of cerrado and eucalyptus, for later analysis of the loss of biomass. The evaluation of the decomposition was done monthly, from October 2015 to September 2016. The results indicated that the percentage of loss of mass in both vegetation was similar. With 12 months of analysis, the cerrado and eucalyptus still had more than $60 \%$ of their initial mass. With a high $\mathrm{C} / \mathrm{N}$ ratio for the two vegetations.
\end{abstract}

Key words: Nutrient cycling, eucalyptus, cerrado, decomposition bags. 


\section{SUMÁRIO}

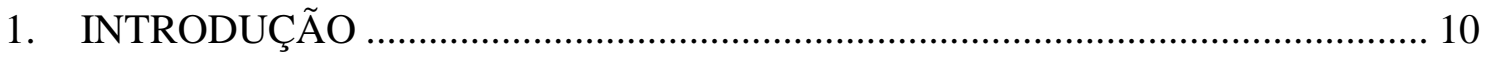

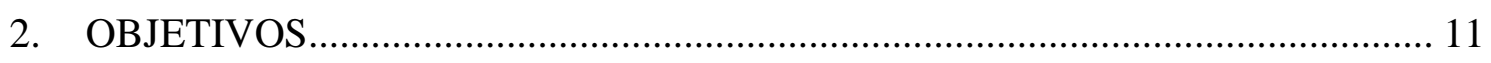

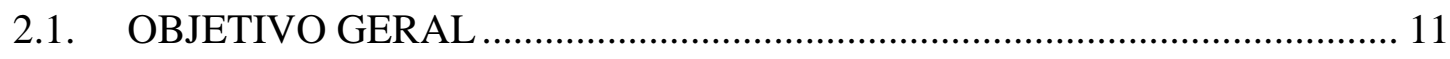

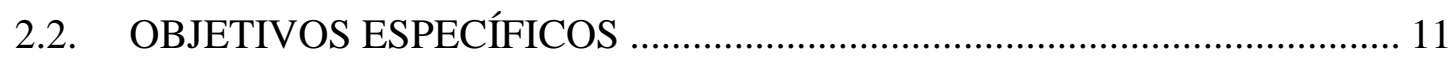

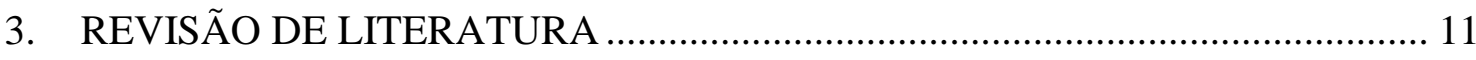

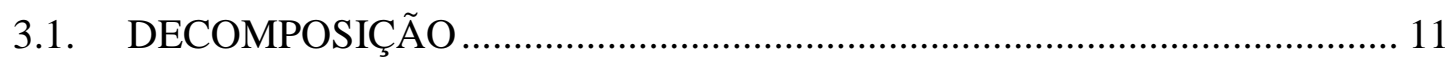

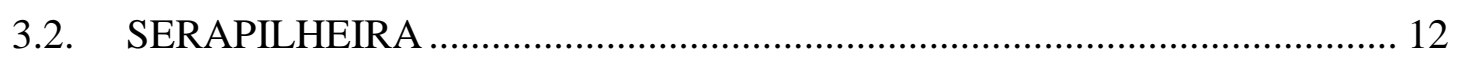

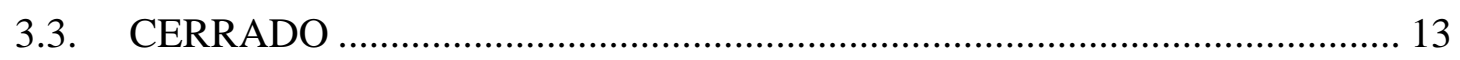

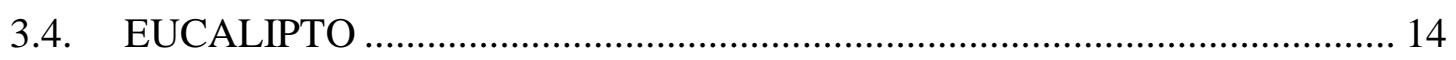

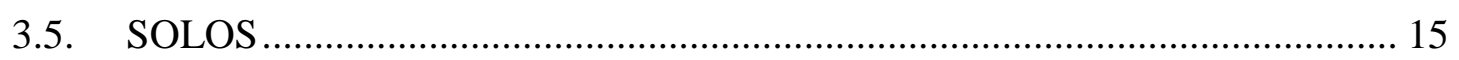

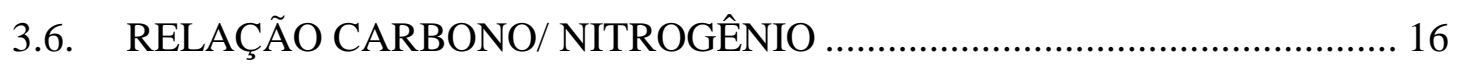

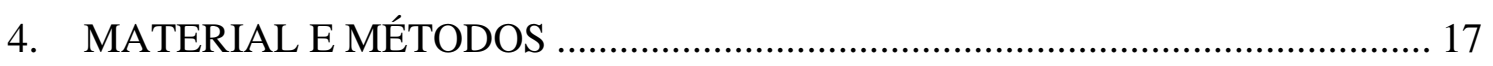

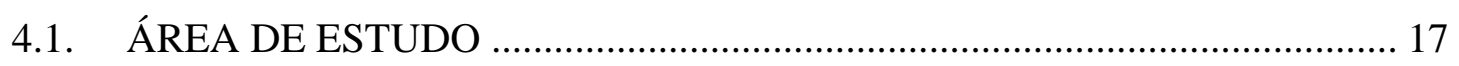

4.2. CARACTERIZAÇÃO DO EXPERIMENTO ….......................................... 20

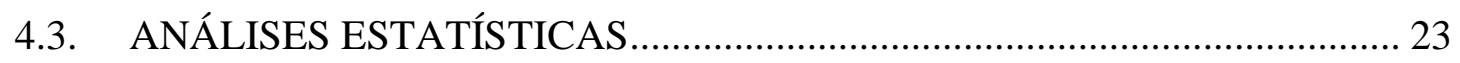

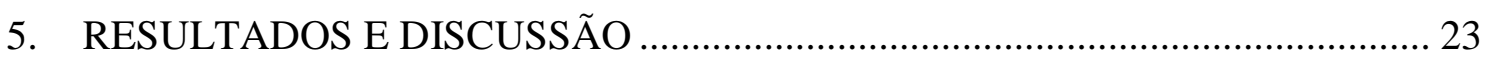

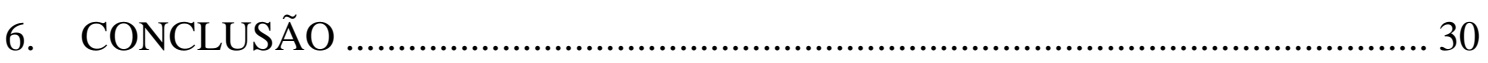

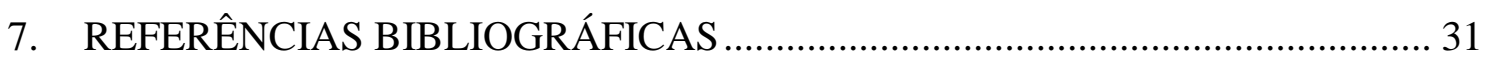




\section{LISTA DE FIGURAS}

Figura 1. Localização regional da área de estudo

Figura 2. Identificação detalhada da área: Cerrado Típico e do Eucalipto na Fazenda Água Limpa. Fonte: MOTA (2017).

Figura 3. Precipitação e temperatura, durante o período de out/2016 a set/2017 de decomposição da serapilheira foliar no cerrado e no eucalipto

Figura 4. Localização dos pontos de coleta de decomposição de serapilheira em cada parcela.

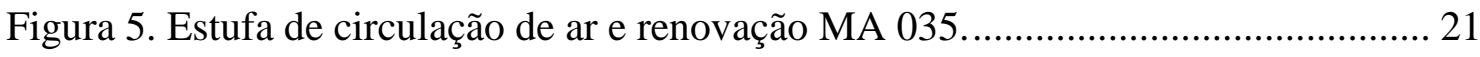

Figura 6. Moinho triturador da serapilheira seca, para análise da relação $\mathrm{C} / \mathrm{N}$ do lado esquerdo. A figura do lado direito mostra a quantidade de serapilheira seca usada no experimento para análise de $\mathrm{C} / \mathrm{N}$.

Figura 7. Regressão exponencial de decaimento de biomassa foliar (g) do Cerrado Típico (A) e eucalipto (B) no período de 360 dias. 


\section{LISTA DE TABELAS}

Tabela 1. Biomassa foliar remanescente das folhas (g) presentes em sacolas de decomposição aos $0,30,60,90,120,150,180,210,240,270,300,330$ e 360 dias nos períodos out/2015- set/2016 no eucalipto e cerrado na Fazenda Água Limpa, BrasíliaDF. 24

Tabela 2. Constante $\mathrm{k}$, tempo de meia vida $\left(\mathrm{T}^{1 / 2}\right)$ e estimativa de biomassa decomposta para o período de 2015-2016 na Fazenda Água Limpa, Brasília-DF. 27 Tabela 3. Médias de Carbono, Nitrogênio e relação $\mathrm{C} / \mathrm{N}$ em porcentagem (\%) para o período de out/2015 a maio/2016. 28 


\section{INTRODUÇÃO}

A diferença entre a deposição e decomposição é que a primeira é o aporte de materiais que caem no solo, ajudando de forma direta a redução de lixiviação dos nutrientes na camada superficial. Já a decomposição é a perda de massa das folhas, ela devolve os nutrientes absorvidos de volta a planta (SHUMACHER et al., 2004).

Para Jaramillo-Botero et al. (2008) a serapilheira possui inúmeras colocações. Uma delas é observada quando há perca da cobertura superficial do solo, ela serve como proteção a esse solo (erosão). O resultado de baixa decomposição está relacionado a eficiência da ciclagem química feita pelo eucalipto, resultando em serapilheira com déficit nutricional. A diversificação da ciclagem nutritiva do solo, tem a possibilidade de promover a sustentabilidade das plantações decorrentes de procedimentos de manejo aplicadas (GAMA-RODRIGUES; BARROS, 2002).

Os principais materiais orgânicos obtidos através da serapilheira são folhas, ramos sementes e flores que ficam depositados na parte superior do solo. A serapilheira é um fator crucial para a recuperação de ambientes degradados, auxiliando no suprimento de nutrientes para o solo (MARTINS, 2009). A partir do balanço dos nutrientes no sentido solo-planta é possível verificar a quantidade produzida por uma floresta de forma sustentável (SANTANA et al., 2008).

O Cerrado é o segundo maior bioma do Brasil. Das muitas fitofisionomias pertencentes a ele, o principal é o cerrado sentido restrito. Esse bioma é composto por vegetação florestais, savânicas e campestres (RIBEIRO; WALTER, 2008). As formações savânicas do bioma são compostas por áreas com árvores e arbustos que ficam espalhados sobre um estrato de gramíneas, onde não há formação de dossel contínuo, englobando o Cerrado sentido restrito, Parque Cerrado, Palmeiral e Vereda, que são os principais tipos fisionômicos dessa formação. Com relação as formações campestres predominam as espécies herbáceas e algumas arbustivas, faltando árvores na paisagem. Campo sujo, Campo rupestre e Campo limpo são os três tipos fisionômicos principais que ocorrem neste tipo de formação (RIBEIRO; DIAS, 2007). Dentre as vegetações que ocorrem no cerrado, o típico é o mais predominante (MARIMONJUNIOR; HARIDASAN, 2005). 


\section{OBJETIVOS}

\subsection{OBJETIVO GERAL}

Avaliar a taxa de decaimento de serapilheira foliar através das variáveis climáticas em vegetação nativa (cerrado típico) e plantio florestal de eucalipto híbridos (urophylla x grandis).

\subsection{OBJETIVOS ESPECÍFICOS}

- Monitorar a decomposição de serapilheira no cerrado e eucalipto, no período de 12 meses;

- Avaliar a relação $\mathrm{C} / \mathrm{N}$ em função do tempo em decomposição.

\section{REVISÃO DE LITERATURA}

\subsection{DECOMPOSIÇÃO}

Para ocorrer todo o ciclo que envolve a decomposição das foliar é preciso que aconteça a liberação dos nutrientes presente nas folhas, e que aconteça a retenção dos nutrientes necessários para as folhas serem decompostas (DUTTA; AGRAWAL, 2001). Conforme citado por Guo e Sims (2002), os tipos de folhas presentes na vegetação, os tipos de espécies envolvidas e a constituição química inicial refletem expressivamente no decaimento foliar e consequentemente na liberação de nutrientes.

Segundo Aber e Melillo (1980) é necessário um maior conhecimento do sistema ecológico da vegetação, para em seguida fazer uma avaliação da produção da serapilheira e da taxa de decaimento das folhas, pois a decomposição é essencial para que os nutrientes e matéria orgânica voltem ao solo. A matéria orgânica morta envolve desde componentes orgânicos e inorgânicos (BEARE et al. 1992). Eles são importantes, pois segundo Moreira e Siqueira (2006) afetam na determinação da quantidade de tempo que leva para o decaimento das folhas. A presença de alto teores de lignina por exemplo implica em uma maior resistência das folhas dificultando a penetração dos organismos no solo.

De acordo com Eira (1995) e Wardle e Lavelle (1997) a decomposição acontece em sua maioria devido a ação das bactérias e devido á biota do solo. Elas têm um composto enzimático adequado mais favorável para que ocorra a redução da serapilheira. Conforme Haag (1987), Pegado et al. (2008) a rapidez que acontece o 
decaimento do material vegetal acumulado, controla o amontoado de serapilheira superficialmente no solo e a quantidade de nutrientes na serapilheira (ADAMS; ATTIWIL, 1986; COSTA et al. 2005; TEIXEIRA et al. 2012). A decomposição das folhas acumuladas e consequentemente a sua produção são os principais tipos de aporte de matéria orgânica e transferência de nutrientes que existe em solos florestais (KONIG et al., 2002; ARATO et al., 2003; SCHUMACHER et al., 2004; BARLOW et al., 2007; PANDEY et al., 2007).

A taxa de decaimento do folhedo altera a transformação da matéria orgânica em inorgânica e através da qualidade dos substratos existentes, em função das iguais condições do solo e do clima (MELLILO et al. 1982, TAYLOR et al. 1989). De forma geral a qualidade do substrato envolve o conteúdo da lignina, aglomeração de nitrogênio e pela razão C: $\mathrm{N}$ de cada material (MOORHEAD et al., 1999).

Um processo diretamente proporcional para aferir a taxa de decomposição foliar é feito através do método de sacolas de decomposição (litterbags). Ele permite a interação interna entre vários tipos de organismos, assim possibilitando um decaimento real do material na superfície do solo. De acordo com Berg e McClaugherty (2003), em relação a perda de massa foliar, com o uso do método de sacolas de decomposição, o experimento pode ser acompanhado até obter valores de 60 a $70 \%$ da perda de biomassa foliar.

A taxa de decaimento em plantações de Eucalyptus sp são baixas, isso implica em acréscimo de nutrientes na interface de serapilheira e o solo, devido ao amontoado de matéria orgânica no solo (ADAMS; ATTIWIL, 1986; LOUZADA et al., 1997; GAMA-RODRIGUES; BARROS, 2002). Conforme Gama-Rodrigues e Barros (2002), o eucalipto apresenta uma boa retranslocação de nutrientes em consequência da baixa taxa de decomposição, por isso sua serapilheira apresenta baixa qualidade de nutrientes, por exemplo nitrogênio e potássio.

\subsection{SERAPILHEIRA}

Uma das principais características da acumulação de aporte no piso florestal é quantidade de serapilheira no solo, isso contribui para o melhoramento do solo em relação aos nutrientes recebidos e para a proteção da camada superficial, não deixando o solo exposto aumentando sua fertilidade (SHUMACHER et al., 2004). Segundo Gama; 
Rodrigues e Barros (2002), devido ao grande efeito do eucalipto na ciclagem dos nutrientes, ele fornece um piso florestal carente em nutrientes.

Schumacher et al., (2003), afirmam que as folhas caídas na superfície do solo desempenham um papel de maior destaque em áreas com baixa fertilidade do solo, solos mais carentes em nutrientes. Um exemplo é o cerrado que possui solo de baixa fertilidade, velhos, tornando a serapilheira depositada no solo o fator principal para fonte de nutrientes (HARIDASAN, 1994).

\subsection{CERRADO}

No Brasil, o Cerrado é o segundo maior bioma em área, sendo superado apenas pela Floresta Amazônica e está situado essencialmente na parte central do país (RIBEIRO; WALTER, 2008). O seu território abrange completamente o Distrito Federal e parte dos Estados de Goiás, Tocantins, Maranhão, Mato Grosso do Sul, Minas Gerais, Mato Grosso, Piauí, São Paulo, Bahia e Paraná (SANO et al., 2010). O Cerrado possui limites com a Amazônia, Caatinga, Floresta Atlântica e com o Pantanal, mantendo uma diversidade de contatos biogeográficos distintos (SILVA; SANTOS, 2005).

O Cerrado é definido como um complexo vegetacional com relações ecológicas e fisionômicas com outras savanas da América tropical, da África e da Austrália (RIBEIRO; WALTER, 1998). Esse bioma apresenta uma grande diversidade de solos e climas, refletindo em uma grande e ainda desconhecida heterogeneidade de biotas (fauna e flora) e, consequentemente, em vários tipos de paisagens e vegetações (DIAS, 1992). É um dos hotpots do mundo, apresentando rica biodiversidade com grande número de espécies animais e vegetais, além do alto grau de endemismo (MITTERMEIER et al., 2005).

O clima no Cerrado varia bastante ao longo do bioma, porém na maior porção do seu território o tipo tropical úmido com o subtipo de savana (Aw) é predominante, caracterizado por apresentar períodos bem definidos de seca (inverno) e chuva (verão), segundo o sistema de classificação de Köppen, a precipitação média anual é de $1.500 \mathrm{~mm}$, que varia entre 750 a 2.000mm (RIBEIRO; WALTER, 1998).

As fisionomias do Cerrado abrangem formações savânicas, florestais e campestres, sendo que nas formações florestais prevalece as espécies arbóreas com 
formação de dossel, contínuo ou descontínuo, composta pelas fisionomias de Mata Ciliar, Mata de Galeria, Mata Seca e Cerradão (RIBEIRO; DIAS, 2007).

A fitofisionomia cerrado sentido típico é a mais conhecida e abrangente do Cerrado (MENDONÇA et al., 2008). Essa fitofisionomia é caracterizada pela presença de árvores baixas, inclinadas, tortuosas, com ramificações irregulares e retorcidas. $\mathrm{O}$ cerrado sentido restrito possui arbustos e subarbustos encontram-se espalhados, com algumas espécies apresentando órgãos subterrâneos perenes (xilopódios). Na época chuvosa as camadas subarbustiva e herbácea tornam-se exuberantes, devido ao seu rápido crescimento (RIBEIRO; WALTER, 2008). De acordo com Felfili e Silva Júnior (2005), a vegetação apresenta elevada riqueza e diversidade alfa, porém a distribuição de indivíduos por espécies é desigual e poucas espécies possuem as maiores populações.

O Cerrado sentido restrito engloba quatro subtipos (Cerrado Denso, Ralo, Típico e Rupestre), sendo que as três primeiras representam variações na forma dos agrupamentos e no espaçamento entre as árvores. Do Cerrado Denso para o Cerrado Ralo a gradação da densidade das árvores é caracterizada como decrescente. Já o Cerrado Rupestre diferencia-se dos demais subtipos por ocorrer, preferencialmente, em solos rasos com a presença de afloramentos de rocha, e por apresentar algumas espécies indicadoras, adaptadas a esse ambiente (RIBEIRO; WALTER, 2008).

Esses diferentes subtipos de Cerrado sentido restrito são influenciados, entre outros fatores, pelas condições edáficas, principalmente baixo $\mathrm{pH}$, alta saturação por alumínio, baixa fertilidade, alta drenagem e pela alta profundidade dos solos, além dos efeitos causados por queimadas recorrentes e pelas ações antrópicas, estrutura da vegetação, que refletem na distribuição espacial dos indivíduos lenhosos e na composição de espécies vegetais (OLIVEIRA FILHO; RATTER, 2002; RIBEIRO; WALTER, 2008).

\subsection{EUCALIPTO}

O gênero Eucalyptus é originário da Austrália, Tasmânia e outras ilhas da Oceania e possui aproximadamente 730 espécies reconhecidas botanicamente, porém, as espécies mais utilizadas no Brasil, em função das características de suas madeiras são: Eucalyptus grandis, Eucalyptus saligna, Eucalyptus urophylla, Eucalyptus 
viminalis, híbridos de E grandis x E urophylla, Eucalytus dunni e Eucalipto benthamii (SANTOROSA et al., 2014).

No Brasil o Produto Interno Bruto (PIB) do setor brasileiro de árvores plantadas alcançou R \$ 69,1 bilhões em 2015, um aumento de 3,0\% em relação ao ano anterior, e dentre as espécies plantadas, o gênero Eucalyptus se destaca no país, possuindo cerca de $72 \%$ da área ocupada das florestas plantadas por ano, o equivalente a 5.630.607 hectares. (IBÁ, 2016). Uma das vantagens de se utilizar a madeira de eucalipto é devido a sua versatilidade, rápido crescimento e madeira de alta densidade básica e tem sido utilizado para diversas finalidades, como produção de lenha, estacas, moirões, celulose e papel, dormentes, chapas de fibras e de partículas, fabricação de casas e móveis (RODIGHERI, 1997; PEREIRA et al., 2000).

O Eucalyptus urophylla tem como característica uma boa forma do fuste, densidade básica de aproximadamente $0,5 \mathrm{~g} / \mathrm{cm}^{3}$, presença de lignotubérculo, boa brotação, a espécie reage ao espaçamento e a adubação realizada, a segunda rotação apresenta bom desenvolvimento e é uma espécie resistente ao déficit hídrico, grande potencial de crescimento em termos de área plantada e resistência ao cancro do eucalipto (Cryphonectria cubensis) (SCANAVACA JUNIOR; GARCIA, 2003; FERREIRA, 1992).

Alguns dos principais fatores que podem restringir a implantação do eucalipto, além dos que estão relacionados ao cultivo mínimo do solo, destacam-se o déficit hídrico, o estresse provocado pelo calor e o choque térmico, o resfriamento e o congelamento, o vento, a salinidade e a deficiência de oxigênio (TAIZ; ZEIGER, 2004). Alguns fatores que influenciam a produtividade dos plantios florestais estão relacionados às propriedades do solo que atuam no suprimento de recursos de crescimento, como a água e os nutrientes, para as árvores, e às propriedades que facilitam o crescimento do sistema radicular (REIS et al., 2006; CORREAA NETO et al., 2007; BALIEIRO et al., 2008).

\subsection{SOLOS}

O solo de forma geral é definido como a camada superficial que recobre a terra, podendo ser vegetativa ou apenas camadas sedimentadas, também conhecido como pedogênese do solo, sendo formado por fatores bióticos e abióticos (GONÇALVES, 
2002). Alvarenga et al., (1998), afirmam que os motivos que influenciam a evolução do solo estão relacionados aos aspectos climáticos (seco e frio) e a sua camada vegetal desenvolvida pelas gramíneas e ao seu tipo de relevo. Por outro lado, altas temperaturas e tempo úmido, auxiliam de forma mais rápida a decomposição de serapilheira, aumentando seu piso florestal, maior presença de nutrientes.

Nos solos do Cerrado, ocorre a presença das classes Latossolo, Neossolo, Argissolo, Plintossolo, Cambissolo, Gleissolo, Nitossolo, Chernossolo, Planossolo e Organossolo, de acordo com o sistema de classificação sugerido pela Embrapa (EMBRAPA, 2013). Em geral, os solos do Cerrado são profundos, com baixa fertilidade natural, acidez acentuada devido a presença de sílica em relevo plano e suavemente ondulado, com boa estrutura para mecanização (BASTOS, 2010).

\subsection{RELAÇÃO CARBONO/ NITROGÊNIO}

A mudança dos ecossistemas naturais para áreas de cultivos modifica a quantidade de teores do carbono orgânico total (COT) no solo. Isso se deve pela relação entre a razão do incremento na taxa de mineralização da matéria orgânica com a emissão dos gases estufas (LAL, 2004, BROWN; LUGO, 1990).

Segundo Ecoar (2003), se bem constituídos, os cultivos de eucalipto chegam a fixar em torno de 100 a $400 \mathrm{t} \mathrm{ha}^{-1}$ de $\mathrm{CO}_{2}$ durante seu desenvolvimento. Conforme pesquisas, há um maior potencial de dreno do $\mathrm{C}$ em vegetação de floresta nos climas tropicais, do que em áreas de uso agrícola. Isso se explica a maior quantidade de deposição anual de biomassa sob o solo da serapilheira e consequentemente de raízes mortas (LAL et al., 1995; KRISHNAMURTHY; ÁVILA, 1999). Segundo Cerri et al., (2001) o C estocado no solo e na vegetação constitui em torno de 20 a $25 \%$ do C global.

De acordo com Silva e Mendonça (2007), os restos vegetais e animais sob cultivos florestais influencia na distribuição de nutrientes ás plantas, na velocidade microbiana, na contenção de cátions e de água no solo, na aeração e estabilidade da estrutura. Essas influências determinam a capacidade produtiva do solo com alta intemperização.

Os principais fatores que dever ser analisados que interfere no aumento das taxas de C orgânico do solo, da estocagem e retenção são: tipos de relevo e drenagem, as condições locais do clima e como são manejados os solos (LAL, 2005; FALLOON et 
al., 2007; SMITH, 2008). O sequestro do C no solo está sujeito a aspectos da vegetação natural ou plantada, as diferentes classes de solo e depende de como são aplicadas o sistema de manejo (SLEUTEL et al., 2006).

Stevenson (1994) diz que, áreas que tem a cobertura vegetal natural, o C orgânico existente permanece em equilíbrio dinâmico no solo, em taxa regulares com o tempo. Quando é feito o cultivo no solo, essa situação muda, um novo equilíbrio é alcançado em função das particularidades do manejo utilizado. O eucalipto é um grande imobilizador e capturador de carbono, levando em consideração que possui um crescimento rápido, e uma eficiente produção de biomassa (GATTO et al., 2010). No cerrado sentido restrito as maiores concentrações de carbono são verificadas na camada subterrânea (PAIVA et al., 2011). A relação C/N avalia o grau de mineralização dos nutrientes. Uma das vantagens da análise da relação $\mathrm{C} / \mathrm{N}$ é que a taxa de decaimento pode ser verificada pela relação $\mathrm{C} / \mathrm{N}$ na serapilheira (SARIYILDIZ e ANDERSON, 2003).

\section{MATERIAL E MÉTODOS}

\section{1. ÁREA DE ESTUDO}

O experimento foi realizado na Reserva Ecológica e Experimental da Universidade de Brasília, Fazenda água Limpa (FAL). Situa-se nas coordenadas 1556' a $15^{\circ} 59^{\prime} \mathrm{S}$ e $47^{\circ} 55^{\prime}$ a $47^{\circ} 58^{\prime} \mathrm{W}$ no Distrito Federal, a $20 \mathrm{~km}$ da capital Brasília (LIBANO; FELFILI, 2006).

A FAL ocupa uma área de 4340 ha, desse total 2340 ha são destinadas a preservação, 800 ha conservação e 1200 ha a produção (FAL, 2013). A fazenda está situada em uma Área de Preservação Ambiental - APA das respectivas Bacias do Gama e Cabeça de Veado. Fica englobada no núcleo da Biosfera do Cerrado e faz fronteira ao norte com o Núcleo Rural Vargem Bonita e com o Ribeirão do Gama e ao sul com a BR 251 que liga Brasília /DF a Unaí /MG, a leste ao córrego Taquara e ao Instituto Brasileiro de Geografia e Estatística - IBGE e a oeste com a estrada de ferro e o Country Club de Brasília (Figura 1). Em conjunto com a Reserva Ecológica do Instituto Brasileiro de Geografia e Estatística e o Jardim Botânico de Brasília totalizam 9000 ha (MTBBRASILIA, 2012). 


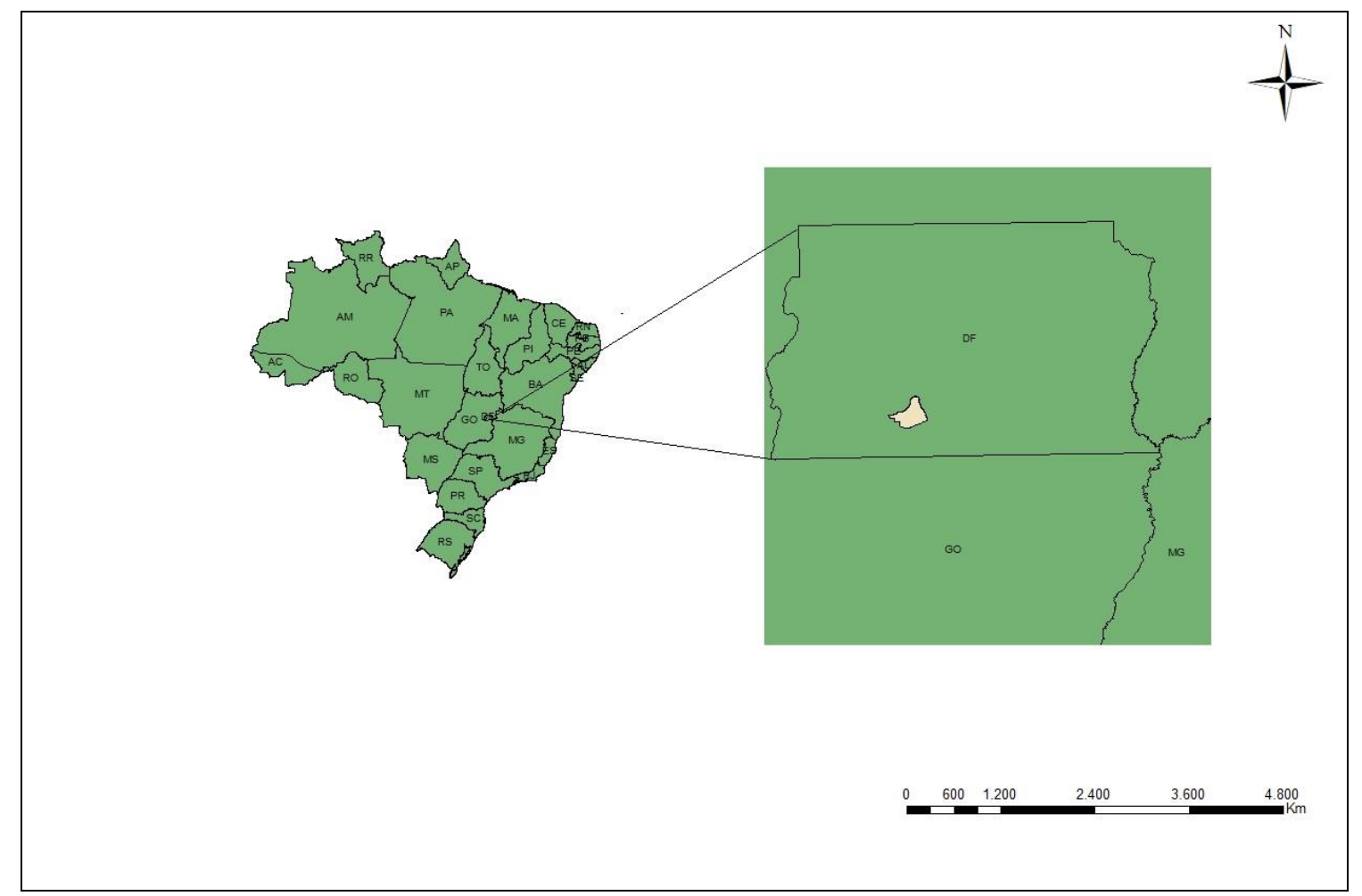

Figura 1. Localização regional da área de estudo

Conforme Felfili (1988) a altitude média é de $1100 \mathrm{~m}$ e pluviosidade média de $1600 \mathrm{~mm}$ com clima denominado do tipo Aw (classificação de Köppen), com duas estações bem definidas, seca e chuvosa. A temperatura média é de $22,1^{\circ} \mathrm{C}$ com precipitação média anual de 1468,6 mm segundo dados meteorológicos da estação climatológica da Reserva Ecológica do Instituto Brasileiro de Geografia e Estatística (Recor-IBGE).

Para Felfili et al. (2000) têm várias fitofisionomias dominantes na FAL entre elas estão o Cerrado sentido restrito, grandes áreas de Campo sujo e Campo limpo. Dentre os diversos tipos de solos, na FAL, predomina o solo do tipo Latossolo vermelho, ácido a muito ácido, com alto teor de alumínio e baixos teores de cálcio e magnésio (LIBANO; FELFILI, 2006). Segundo Felfili e Silva Júnior (1988) na FAL o cerrado sentido restrito, apresenta uma faixa de 148 ha $(400 \times 3700 \mathrm{~m})$.

O experimento foi desenvolvido em duas áreas de formação vegetativa. Uma delas é o cerrado sentido restrito e a outra área é um povoamento de eucalipto. A plantação de eucalipto é formada de pelo híbrido clonal (urophylla $x$ grandis). Nas duas vegetações fez-se o procedimento de instalação de parcelas para serem monitoradas 
durante o período da pesquisa. Sendo que para o cerrado foram instaladas 12 parcelas com espaçamento de $20 \mathrm{~m}$ x $50 \mathrm{~m}$, de modo aleatório, cobrindo toda a sua extensão $(1,2$ ha).

Para o povoamento de eucalipto, com área total de 23 ha, em um espaçamento de $3 \mathrm{~m}$ x $3 \mathrm{~m}$ foram alocadas de modo sistemático 21 parcelas de $15 \mathrm{~m}$ x $30 \mathrm{~m}$ (Figura 2). Esta área teve todos os preparos de solos cabíveis ao local, como subsolagem, fertilização e adubação. (MOTA, 2017). Para avaliar a decomposição da serapilheira nas duas vegetações foram escolhidas 5 parcelas em cada uma das vegetações de modo aleatório.

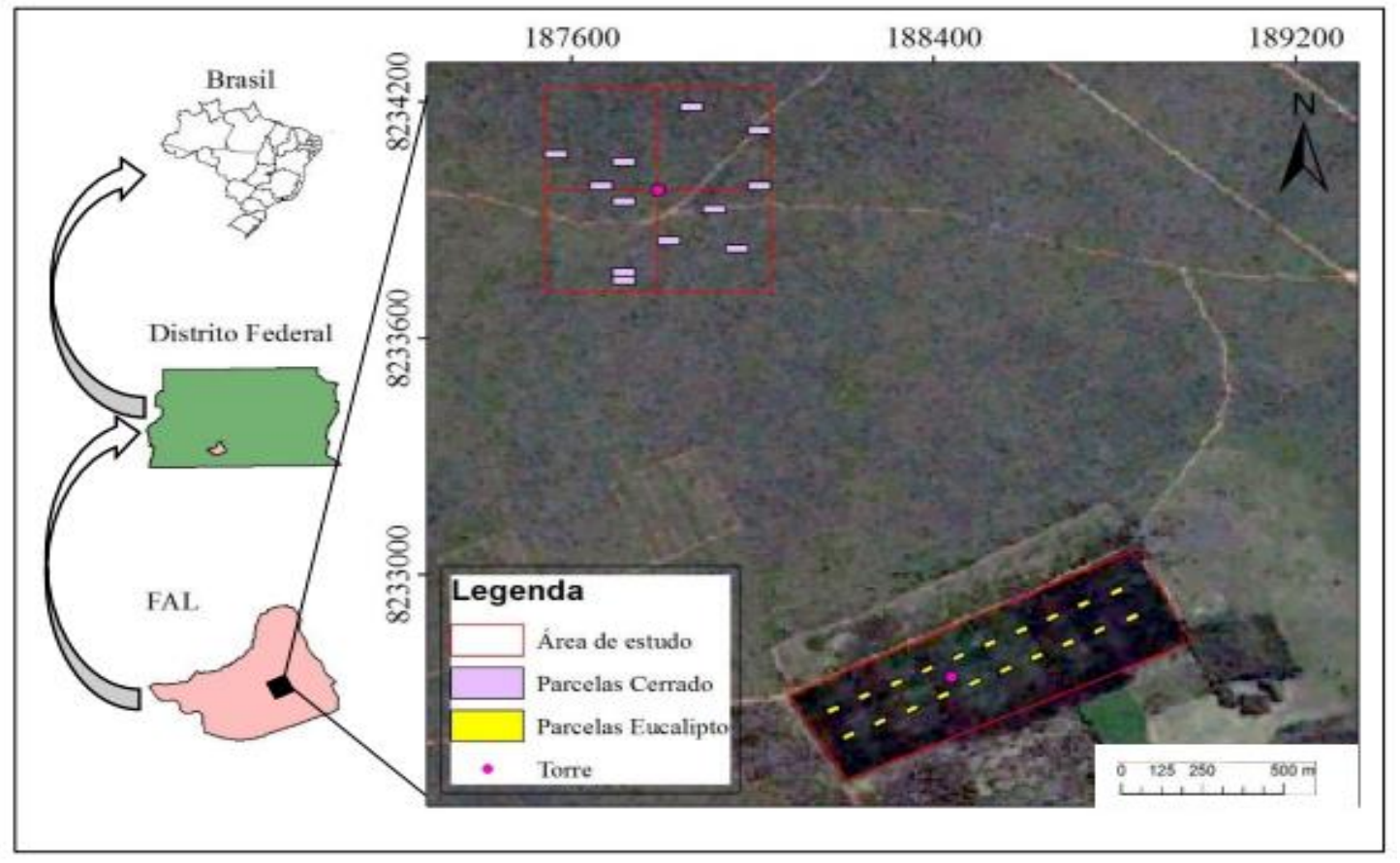

Figura 2. Identificação detalhada da área: Cerrado Típico e do Eucalipto na Fazenda Água Limpa. Fonte: MOTA (2017).

Nessa pesquisa também foram utilizados dados obtidos por meio da estação meteorológica da FAL (Figura 3), situada no Laboratório de Agroclimatologia da Faculdade de Agronomia e Veterinária (FAV), localizada na sede da FAL, tem-se a estação meteorológica convencional e outra automática disponível para pesquisas, disponibilizada no site http://www.fav.unb.br/laboratorios/laboratorio-deagroclimatologia (FAL, 2017). As variáveis meteorológicas foram coletadas por meio da estação meteorológicas da FAL no período de outubro/2015 a maio/2016. 


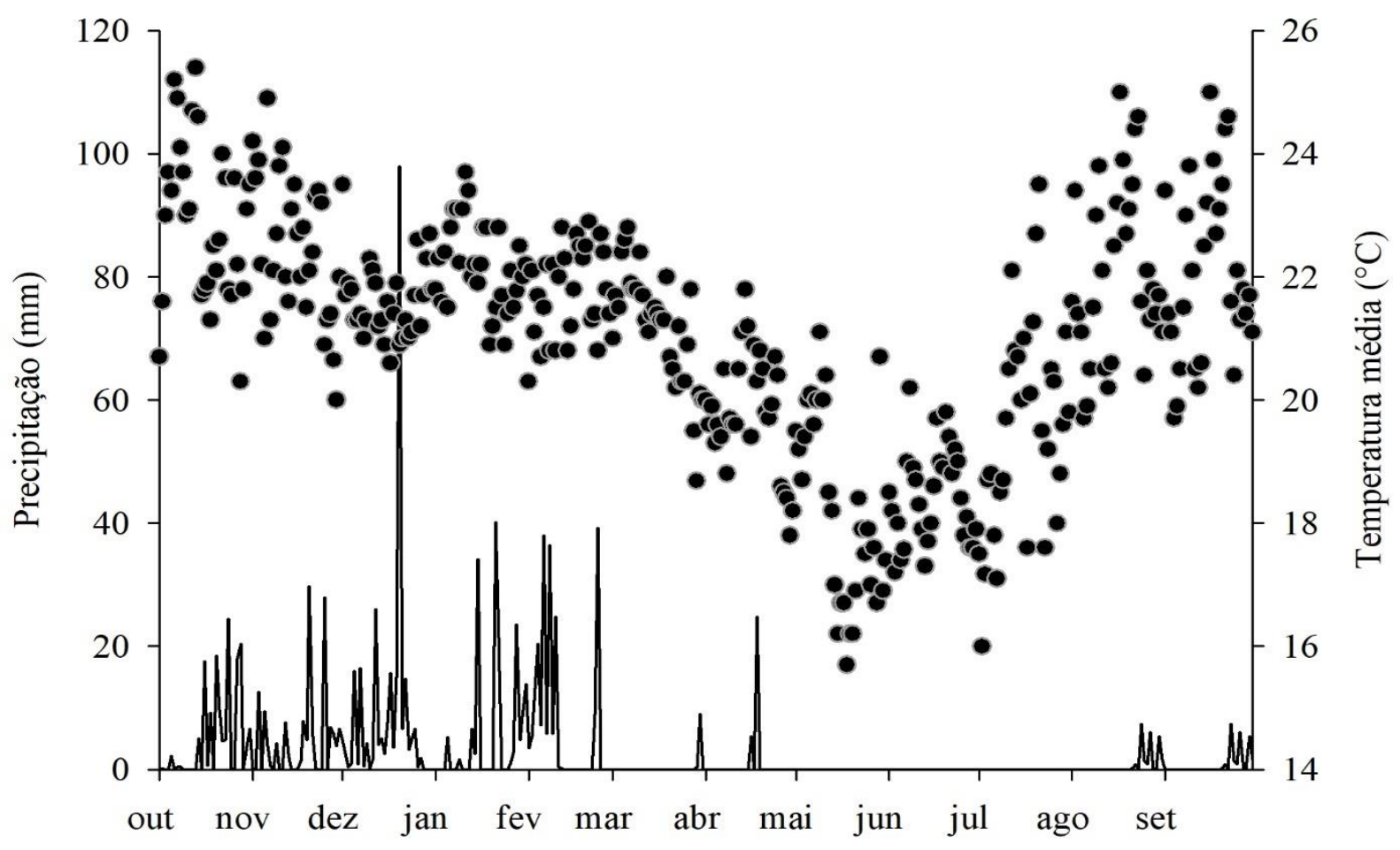

Figura 3. Precipitação e temperatura, durante o período de out/2016 a set/2017 de decomposição da serapilheira foliar no cerrado e no eucalipto.

\subsection{CARACTERIZAÇÃO DO EXPERIMENTO}

Foram coletadas, no período de agosto de 2015, folhas recém caídas nas duas vegetações. Para a área do eucalipto, essas folhas apresentavam formato lanceoladas a falciformes, alternadas e estreitas, para a área de cerrado, as folhas apresentaram formatos diversos e diferentes tamanhos, devido à variedade de espécies no mesmo ambiente. Em seguida, essas folhas foram alocadas em bolsas feitas de nylon de $1 \mathrm{~mm}$ de malha, com dimensão de $20 \mathrm{~cm}$ x $20 \mathrm{~cm}$ (ANDERSON; INGRAM, 1996), denominadas de sacolas de decomposição (litterbags) desenvolvido por (BOCOCK; GILBERT, 1957), que continham em cada amostra $20 \mathrm{~g}$ de folhas que foram realocadas novamente nas áreas de cerrado e eucalipto. As sacolas de decomposição permitem analisar de forma direta a taxa de decaimento, por meio da perda de massa foliar ao longo do experimento (SCORIZA et al., 2012).

Para as duas vegetações analisadas, foram escolhidas 5 parcelas de forma aleatória para instalar as bolsas de decomposição. A avaliação da decomposição de 
serapilheira foliar foi feita mensalmente, no período de outubro de 2015 a setembro de 2016 de modo que foram retiradas quatro sacolas de decomposição por parcela nos três pontos escolhidos de cada parcela, diagonal superior da parcela (A), centro da parcela (B) e na diagonal inferior (C) (Figura 4). No final, foram obtidas mensalmente 20 bolsas de litter-bags para o cerrado e 20 na área do eucalipto.

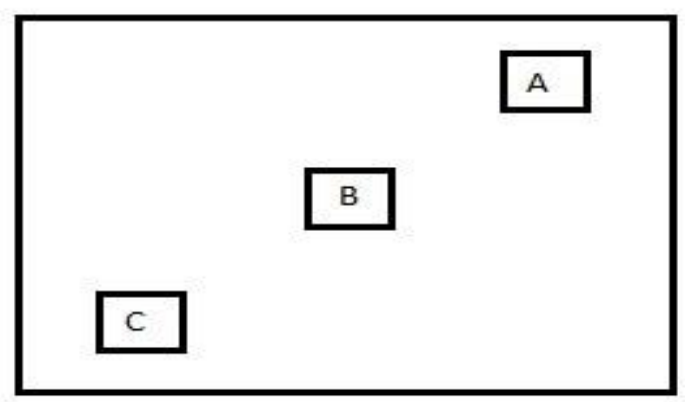

Figura 4. Localização dos pontos de coleta de decomposição de serapilheira em cada parcela.

Para a análise da decomposição de serapilheira foliar é fundamental saber o peso seco das folhas. Logo, após a coleta foi feita a pesagem em uma balança de precisão 0,01 g para saber o peso úmido de cada amostra. Para obtenção do peso seco, as amostras coletas foram colocadas em estufa de circulação de ar e renovação, aquecidas a $62^{\circ} \mathrm{C}$ por um período de 72 horas (Figura 5). Esse processo foi seguido durante todo o experimento.

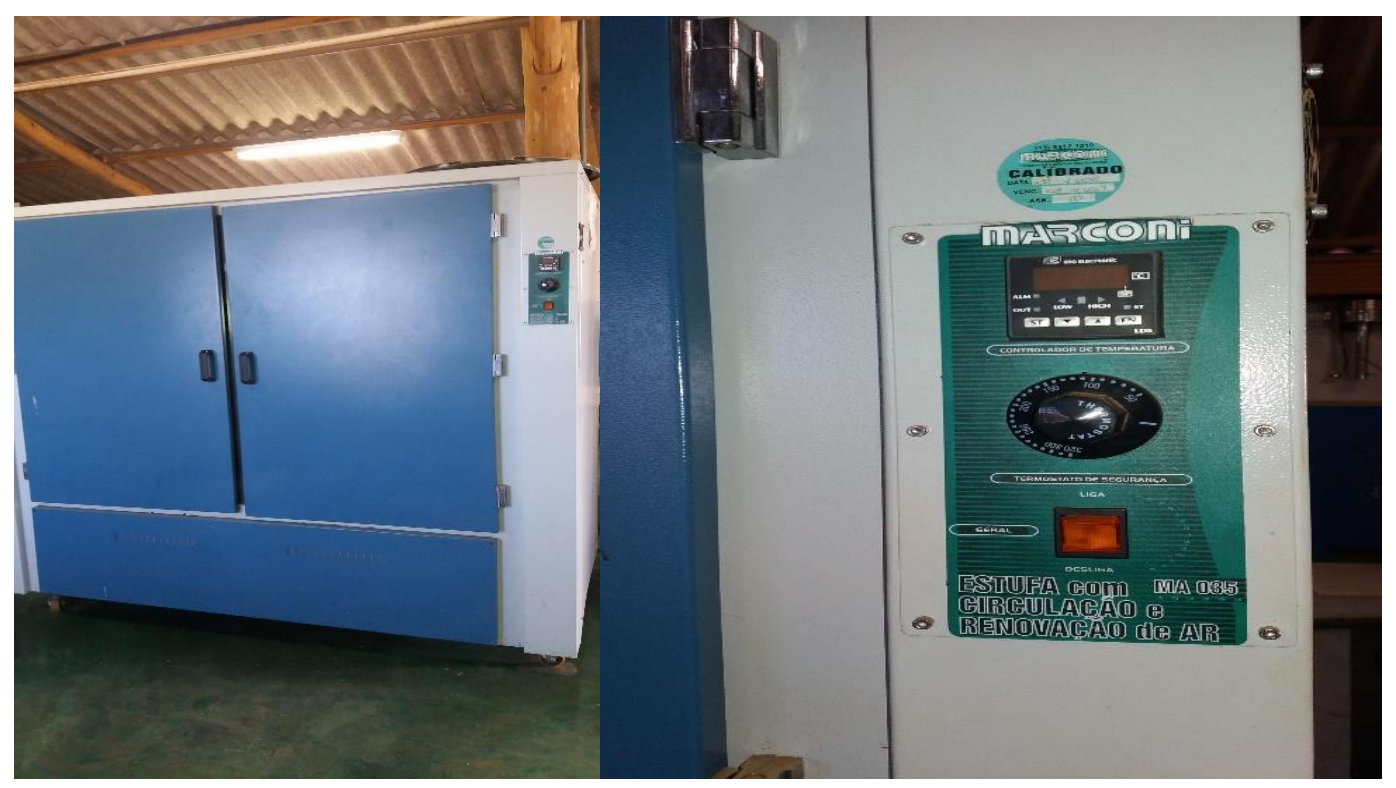

Figura 5. Estufa de circulação de ar e renovação MA 035. 
A decomposição do material foliar foi calculada em função das perdas médias de biomassa ao longo do tempo com a seguinte equação: massa remanescente $(\%)=$ (massa final/massa inicial) $\times 100$. Para obter a constante $\mathrm{k}$ foi utilizada a equação exponencial proposta por Olson (1963), em que $\mathrm{Xt}=\mathrm{X} 0 . \mathrm{e}-\mathrm{kt}$, $(\mathrm{Xt}=$ peso seco do material remanescente após $\mathrm{t}$ dias e $\mathrm{X} 0=$ peso seco do material em $\mathrm{t}=0$ ). $\mathrm{O}$ cálculo do tempo de meia vida também foi aplicado conforme Olson (1963) pela equação $T^{1 / 2}=\ln (2) / k(k=$ constante de decomposição).

As etapas de trituração das folhas para obtenção dos valores de $\mathrm{C} / \mathrm{N}$, foi feita da seguinte forma: depois de secas as amostras, faz-se a junção dos quatro litter-bags formando uma única amostra para cada uma das cinco parcelas escolhidas para os dois estratos, totalizando 10 amostras. Em seguida o material foi triturado individualmente no moinho (Figura 6) para a coleta da amostra de serapilheira decomposta para futura análise.

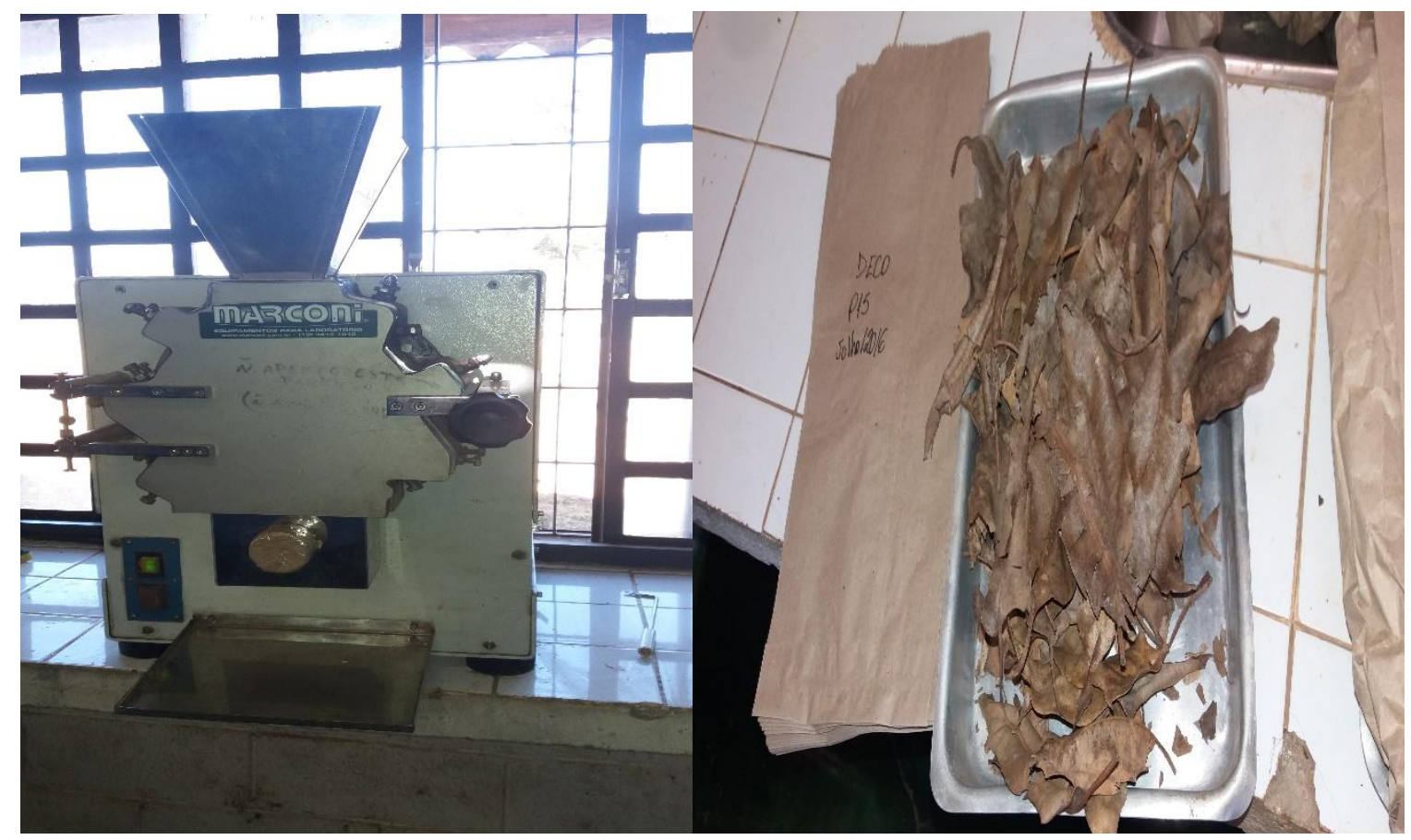

Figura 6. Moinho triturador da serapilheira seca, para análise da relação $\mathrm{C} / \mathrm{N}$ do lado esquerdo. A figura do lado direito mostra a quantidade de serapilheira seca usada no experimento para análise de $\mathrm{C} / \mathrm{N}$

O tempo da análise ocorreu durante 12 meses e os valores encontrados de biomassa seca para hectare foram feitos através da quantificação de Carbono/Nitrogênio $(\mathrm{C} / \mathrm{N})$ com o uso do equipamento CN628 Leco®. 


\subsection{ANÁLISES ESTATÍSTICAS}

Dentre as análises de variância, nesse experimento optou-se pela one-way ANOVA. Foi aplicado o teste $t$ de Tuckey a 5\% de significância para avaliar as médias obtidas e o teste F de Welch para variâncias desiguais (ZAR, 2010). Fez o teste de normalidade (teste de Levene), homogeneidade (teste Shapiro-Wilk) e regressão exponencial para obter a taxa de biomassa. Em relação as análises abordadas, todas foram realizadas com o auxílio do programa PAST 2.15 (HAMER; HARPER; RYAN, 2001).

\section{RESULTADOS E DISCUSSÃO}

O tempo de análise de doze meses foi pouco para afirmar qual vegetação possui maior taxa de decomposição, devido a flutuação de valores e a não variabilidade sazonal das informações. Várias variáveis climáticas devem ser levadas em consideração para estudo da decomposição: temperatura, precipitação, umidade do solo e teor de nitrogênio $(\mathrm{C} / \mathrm{N})$. Essas variáveis influenciam na taxa de decomposição da serapilheira, como a qualidade do material, outro importante atributo que interfere na taxa de decaimento. A decomposição depende de vários atributos do solo, clima e atividades dos organismos (HEAL et al., 1997; CORREIA e ANDRADE, 1999)

A região de estudo apresenta regime de precipitação bem definido. A estação chuvosa tem início em outubro e estende-se até março e estação seca acontece desde abril até setembro. O período de seca e chuva influência no decaimento da serapilheira, observando a Tabela 1 infere-se que a vegetação que se decompôs mais rápido e apresentou menores taxas de decomposição foi o eucalipto. Possivelmente devido à idade do povoamento, luminosidade, temperatura, precipitação e relação $\mathrm{C} / \mathrm{N}$, pois são variáveis que interferem na quantidade de serapilheira decomposta (BARRETO et al., 2008, 2010; FARIA et al., 2008). 
Tabela 1. Biomassa foliar remanescente das folhas (g) presentes em sacolas de decomposição aos 0, 30, 60, 90, 120, 150, 180, 210, 240, 270, 300, 330 e 360 dias nos períodos out/2015- set/2016 no eucalipto e cerrado na Fazenda Água Limpa, BrasíliaDF.

\begin{tabular}{ccc}
\hline $\begin{array}{c}\text { Período } \\
\text { (Dias) }\end{array}$ & $\begin{array}{c}\text { Decomposição } \\
\text { Cerrado (g) }\end{array}$ & $\begin{array}{c}\text { Decomposição } \\
\text { Eucalipto (g) }\end{array}$ \\
\hline 0 & $20(100 \%) \mathrm{Aa}$ & $20(100 \%) \mathrm{Aa}$ \\
30 & $19,16(95,8 \%) \mathrm{ABa}$ & $18,37(91,85 \%) \mathrm{ABb}$ \\
60 & $18,44(92,2 \%) \mathrm{ACa}$ & $16,9(84,5 \%) \mathrm{ACb}$ \\
90 & $17,84(89,2 \%) \mathrm{ADa}$ & $15,97(79,85 \%) \mathrm{ADb}$ \\
120 & $17,29(86,45 \%) \mathrm{BCDEa}$ & $15,93(79,65 \%) \mathrm{BCDb}$ \\
150 & $16,26(81,3 \%) \mathrm{CDFa}$ & $15,82(79,1 \%) \mathrm{BCDa}$ \\
180 & $15,65(78,25 \%) \mathrm{DGa}$ & $14,84(74,2 \%) \mathrm{DEb}$ \\
210 & $15,29(76,45 \%) \mathrm{DHa}$ & $14,11(70,55 \%) \mathrm{Ea}$ \\
240 & $15,19(75,95 \%) \mathrm{EFGHa}$ & $13,93(69,65 \%) \mathrm{Eb}$ \\
270 & $14,86(74,3 \%) \mathrm{FGHa}$ & $13,86(69,3 \%) \mathrm{Ea}$ \\
300 & $14,85(74,25 \%) \mathrm{FGHa}$ & $14,01(70,05 \%) \mathrm{Eb}$ \\
330 & $14,55(72,75 \%) \mathrm{FGHa}$ & $13,85(69,25 \%) \mathrm{Ea}$ \\
360 & $13,6(68 \%) \mathrm{FGHa}$ & $13,75(68,75 \%) \mathrm{Ea}$ \\
\hline
\end{tabular}

Médias seguidas da mesma letra maiúscula na coluna e minúscula na linha não diferem entre si.

No final do experimento o eucalipto decompôs $31,25 \%$ da sua massa total inicial (20 g), e o cerrado $32 \%$ da massa inicial. Valores similares também foram obtidos por Costa et al., (2005), que no final do tempo de análise de decaimento foliar o Eucalyptus grandis tinha perdido em torno de $30 \%$ da sua massa inicial. A biomassa remanescente foliar analisada entre outubro de 2015 e setembro de 2016 foi de $68 \%$ para o cerrado e $68,75 \%$ para o eucalipto. Guo e Sims (2001) obtiveram para o plantio de Eucalyptus globulus um decaimento de 53,9; 66,9, e 58,5 \% para um tempo de 12 meses de análise, com idade distintas, 1, 2 e 3 anos. Outro experimento na Índia, também teve taxa de biomassa decomposta similar, um Eucalyptus tereticornis de seis anos perdeu 64\% da sua massa (SANKARAN,1993).

Geralmente são encontradas baixas taxas de decomposição em eucalipto, como citado por Adams e Attiwil (1986), Louzada et al., (1997), Gama Rodrigues e Barros (2002), isso faz com que aumente a camada de serapilheira no solo. Isso pode ser explicado em virtude da boa ciclagem bioquímica apresentada pelo eucalipto, resultando em qualidade nutricional de nutrientes baixa (GAMA-RODRIGUES e BARROS, 2002), provocando a imobilização desses (GATTO et al., 2010). No gênero eucalipto a perda de biomassa foliar é menor que $50 \%$ em um ano, levando em consideração as condições edafoclimáticas e sob distintos sistemas de manejo. 
(ADAMS; ATTIWIL 1986; LOUZADA et al., 1997; GAMA-RODRIGUES et al., 2002).

Com base na Tabela 1, nota-se que o cerrado e eucalipto tiveram um comportamento similar nos primeiros meses. Ambos só diferiram significativamente do valor inicial da sacola de decomposição a partir de 90 dias depois do experimento. $\mathrm{O}$ cerrado se estabilizou a partir de 210 dias, então de 210 a 360 dias a perda de massa não teve diferença significativa de permanência do solo, os últimos meses de análise são meses de seca, ou seja, menores temperatura, umidade do solo e precipitação. Observando o eucalipto percebe-se que este apresentou um padrão de decaimento mais regular se estabilizando em 180 dias após o experimento. No entanto se estabilizou mais rápido que o cerrado, pode-se inferir pelos dados que a diferença de decomposição das duas vegetações foi de 30 dias aproximadamente para o período analisado e nas condições edafoclimáticas do experimento.

As maiores perdas de massa no início do experimento, possivelmente deve-se a elevados teores de materiais solúveis presentes no início e também a ação dos microrganismos decompositores (SONGWE et. al; 1995). A partir da análise de decaimento pelo método da sacola de decomposição é possível criar gráficos (Figura 7), que evidenciam curvas do decaimento foliar e também possibilita a análise da liberação dos nutrientes no decorrer do tempo (SCORIZA et al., 2012). Essa curva mostra que a serapilheira foliar e o sistema decompositor e sofre oscilação ao longo do tempo, que interferem na quantidade de biomassa decomposta. As curvas permitem compreender visualmente a decomposição em um intervalo de tempo além de gerar a constante $\mathrm{k}$ (SCORIZA et al., 2012). A figura 7 mostra os resultados obtidos da análise de regressão usando o modelo exponencial para os dois ambientes. 

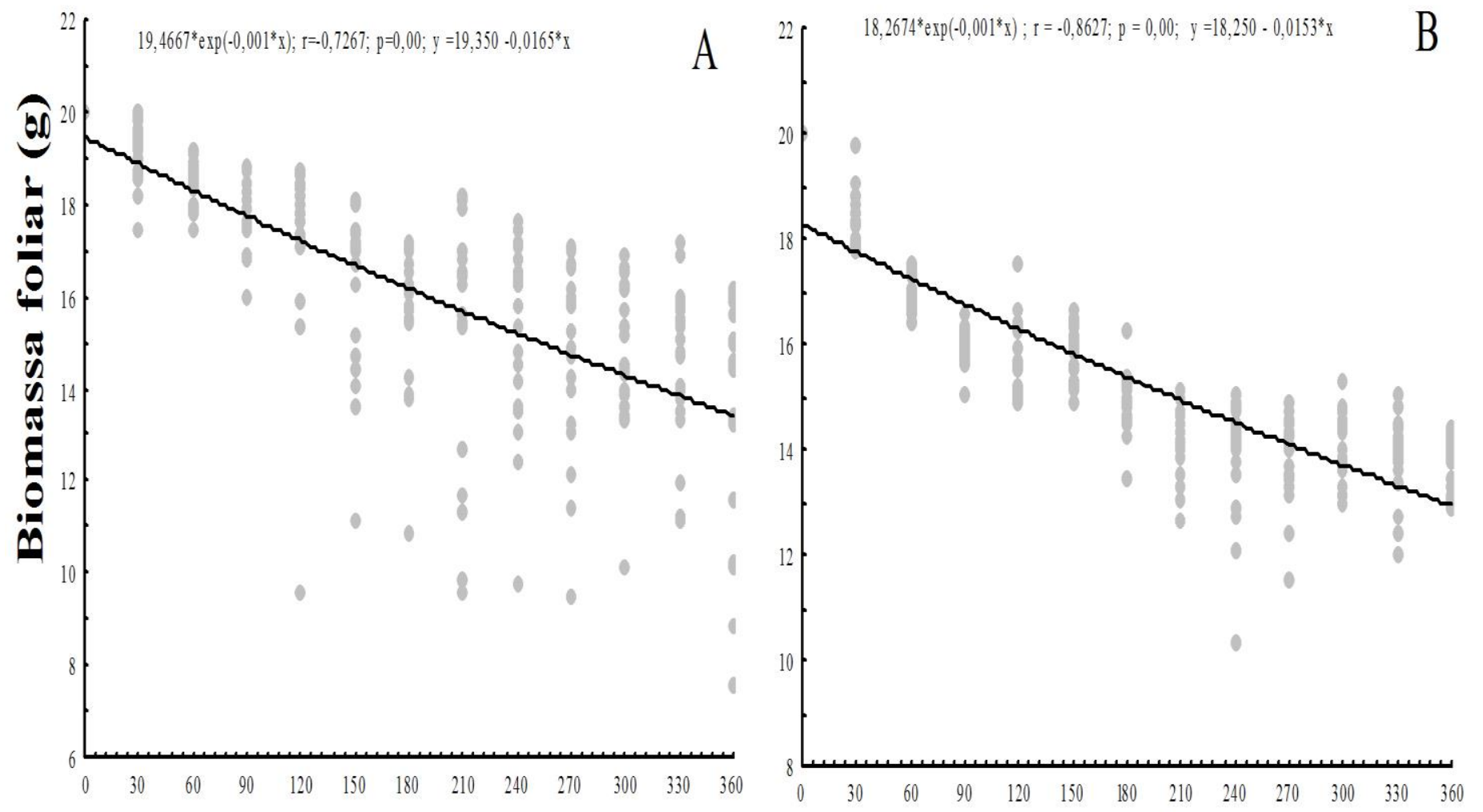

\section{Dias}

Figura 7. Regressão exponencial de decaimento de biomassa foliar (g) do Cerrado Típico (A) e eucalipto (B) no período de 360 dias.

No período chuvoso, apresenta os maiores índices de precipitação, influenciando de forma significava na quantidade de decomposição da serapilheira, essa relação foi encontrada também por Teixeira et. al., (2001). Na época da seca a decomposição é mais lenta, pois diminui a umidade do solo (déficit hídrico) e tem menor atividade dos organismos do solo (não decompõe). Pelo fato dos litterbags terem sido instalados no mês de novembro, e por ser o início da estação chuvosa, a maior umidade e a maior temperatura desta época podem ter influenciado no processo de decomposição foliar do material (POGGIANI et al. 1998).

Conforme Odum (1986), vegetação que possuiu as copas fechadas, a quantidade de luz que chega no solo de uma floresta é reduzida, e a temperatura é uma das variáveis que influencia na perda de massa da decomposição da serapilheira. Larcher (1986) 
afirma em suas pesquisas que a aeração do solo, favorece o decaimento da serapilheira. Temperaturas mais elevadas interfere positivamente na decomposição (SCHUMACHER, 1992), ou seja, quanto maior a temperatura, maior a perda de massa da matéria orgânica.

A análise de variância revelou ausência de diferenças significativas entre as fitofisionomias quanto à perda de massa. Foi decomposto nesse período de análise para o cerrado 1,60 $\mathrm{Mg} \mathrm{ha}^{-1}$ e 1,56 $\mathrm{Mg} \mathrm{ha}^{-1}$ para o eucalipto (Tabela 2), porém não foram encontradas diferenças estatisticamente significativas entre os dois experimentos após 12 meses de decomposição.

Tabela 2. Constante $\mathrm{k}$, tempo de meia vida $\left(\mathrm{T}^{1 / 2}\right)$ e estimativa de biomassa decomposta para o período de 2015-2016 na Fazenda Água Limpa, Brasília-DF.

\begin{tabular}{|c|c|c|}
\hline \multicolumn{3}{|c|}{2015 - 2016} \\
\hline & Cerrado & Eucalipto \\
\hline Equaçãa & $X_{t}=19,4667 * e^{0}{ }^{0,001}$ & $X_{t}=18,2674 * e^{-0,001}$ \\
\hline$K$ & 0,001 & 0,001 \\
\hline $\mathbf{T}^{1 / 2}($ dias$)$ & 693 & 693 \\
\hline $\begin{array}{l}\text { Biomassa decomposta } \\
\left(\mathrm{Mg} \mathrm{ha}^{-1}\right)\end{array}$ & 1,60 & 1,56 \\
\hline
\end{tabular}

Com base nos litterbags, que medem a perda direta de massa a constante $\mathrm{k}$ encontrada foi de 0,001 para ambas as vegetações, sendo que esta constante é a relação entre a quantidade de folha que caiu do dossel e a que está depositada sobre o solo (ANDRADE, 1997). Para o cerrado e o eucalipto o tempo de meia vida $\left(T^{1 / 2}\right.$ ) foi de 693 dias. Infere-se, que em ambos os estratos a perda de biomassa nos períodos amostrados tiveram um tempo de decomposição semelhante, isso se deve ao tempo de meia vida gasto para o decaimento, quanto maior o $\mathrm{T}^{1 / 2}$ maior o tempo gasto para o material se decompor.

Os meses que tiveram o maior índice de chuva, foram os que apresentou maior decomposição e os meses do período seco mostrou-se uma menor decomposição influenciados possivelmente pelas variáveis climáticas temperatura, precipitação, umidade do solo e relação C/N. Coûteaux et al., (1995) e Smith e Bradford (2003) afirmam que os elementos cruciais que atuam no decaimento da serapilheira envolvem a qualidade da serapilheira, os fatores climáticos e os próprios mecanismos decompositores. Costa et. al., (2005) constataram maior decomposição no período que 
apresenta elevadas concentração de chuvas, verificando uma alta influência da variável climática precipitação nas perdas de massa foliar.

Corroborando com os resultados dessa pesquisa Lavelle et al., (1993) citam que a umidade e a temperatura influenciam diretamente no quantidade e qualidade da serapilheira. Luizão (1982), também realizou um trabalho com bolsas de decomposição, e constatou que na estação chuvosa a perda e velocidade de decomposição é maior.

Entre os dois ambientes estudados, observou-se que em mais de $50 \%$ do experimento a decomposição do eucalipto foi superior à do cerrado. Isso decorre possivelmente nessa vegetação, pela idade do plantio, por ser um eucalipto jovem a serapilheira se decompõe mais rápido e mais fácil do que em um eucalipto mais velho, devido a qualidade nutricional do solo, a características do material, a fauna edáfica ou relação $\mathrm{C} / \mathrm{N}$ diferente, além da incidência de luz que entra no povoamento. A luz favorece a taxa de decomposição em eucalipto, sendo que o dossel fechado dificulta essa taxa de decaimento. Vieira et al., (2009) afirmam que a idade das árvores, a qualidade do material genético e sua capacidade de produção interfere na acumulação superficial da serapilheira.

Quanto menor a relação $\mathrm{C} / \mathrm{N}$ mais atrativo é para os organismos do solo e mais fácil se decompõe a serapilheira. A Tabela 3, mostrou que a relação $\mathrm{C} / \mathrm{N}$ no eucalipto é maior que no cerrado, isso se explica ao fato da maioria da serapilheira ser composta por folhas, e a serapilheira foliar tem uma alta relação $\mathrm{C} / \mathrm{N}$, ou seja uma decomposição lenta.

Tabela 3. Médias de Carbono, Nitrogênio e relação C/N em porcentagem (\%) para o período de out/2015 a maio/2016.

\begin{tabular}{ccccccc}
\hline Períodos & \multicolumn{2}{c}{$\mathbf{C}(\%)$} & \multicolumn{2}{c}{$\mathbf{N}(\%)$} & \multicolumn{2}{c}{ C/N (\%) } \\
\hline Meses & Cerrado & Eucalipto & Cerrado & Eucalipto & Cerrado & Eucalipto \\
Out/15 & $50,67 \mathrm{aAB}$ & $51,21 \mathrm{aAB}$ & $0,83 \mathrm{aA}$ & $0,51 \mathrm{bB}$ & $61,09 \mathrm{bA}$ & $99,72 \mathrm{Aa}$ \\
Nov/15 & $50,64 \mathrm{aAB}$ & $51,90 \mathrm{aAB}$ & $0,76 \mathrm{aA}$ & $0,69 \mathrm{aAB}$ & $66,18 \mathrm{aA}$ & $76,09 \mathrm{Aab}$ \\
Dez/15 & $50,46 \mathrm{bAB}$ & $51,84 \mathrm{aA}$ & $0,76 \mathrm{aA}$ & $0,66 \mathrm{bAB}$ & $66,22 \mathrm{bA}$ & $78,43 \mathrm{Aab}$ \\
Jan/16 & $46,43 \mathrm{aB}$ & $46,66 \mathrm{aB}$ & $0,81 \mathrm{aA}$ & $0,57 \mathrm{bAB}$ & $57,20 \mathrm{bA}$ & $80,77 \mathrm{Aab}$ \\
Fev/16 & $48,87 \mathrm{aAB}$ & $49,18 \mathrm{aAB}$ & $0,84 \mathrm{aA}$ & $0,68 \mathrm{bAB}$ & $58,05 \mathrm{bA}$ & $72,15 \mathrm{Aab}$ \\
Mar/16 & $48,80 \mathrm{aAB}$ & $49,97 \mathrm{aAB}$ & $0,88 \mathrm{aA}$ & $0,76 \mathrm{aAB}$ & $55,67 \mathrm{bA}$ & $65,75 \mathrm{Aab}$ \\
Abr/16 & $49,83 \mathrm{bAB}$ & $51,11 \mathrm{aAB}$ & $0,85 \mathrm{aA}$ & $0,81 \mathrm{bAB}$ & $58.16 \mathrm{bA}$ & $62,75 \mathrm{Aab}$ \\
Mai/16 & $50,92 \mathrm{aA}$ & $50,49 \mathrm{aAB}$ & $0,88 \mathrm{aA}$ & $0,84 \mathrm{aA}$ & $57,53 \mathrm{aA}$ & $60,01 \mathrm{Ab}$ \\
\hline
\end{tabular}

Médias seguidas da mesma letra maiúscula na coluna e minúscula na linha não diferem entre si. 
As taxas foram altas para as duas vegetações, porém, o eucalipto ainda se destaca, variando de 60,01 a 99,72 \% e o cerrado varia de 55,67 a 66,22 \%. São considerados uma relação $\mathrm{C} / \mathrm{N}$ alta valores maiores que 30 , estes são considerados materiais de difícil decomposição, explicando a baixa decomposição do cerrado e do eucalipto. Em estudo de Moreira e Siqueira (2006) eles afirmam que relação C/N maior que 30, o processo de imobilização do nitrogênio domina em razão da mineralização dos nutrientes. Uma boa decomposição apresenta valores menores que 20 e é considerada uma rápida decomposição valores menores que 10. Em trabalhos realizados por Louzada et al. (1997); Skorupa, (2001), eles também encontraram maior relação C/N no eucalipto, alterando de 30/1 a 100/1.

Essa relação $\mathrm{C} / \mathrm{N}$ alta do eucalipto, indica geralmente, que esse material é de um eucalipto com idade elevada, ou que já se encontre no ciclo biogeoquímico, com folhas coriáceas (altos teores de lignina, celulose, hemicelulose), com baixos teores de nutrientes na sua folha. Barreto et al., (2008) e Faria et al., (2008) constataram que menores valores das relações celulose: $\mathrm{N}$ e lignina: $\mathrm{N}$ foi encontrado em plantações de eucalipto novo, e maiores em eucaliptos velhos. Isso proporciona um maior nível de resistência da decomposição (COSTA et al., 2005; MONTEIRO; GAMARODRIGUES, 2004).

Dentre as variáveis estudadas ( $\mathrm{C}$ e $\mathrm{N})$, o carbono apresentou maiores valores. Esse resultado pode ser explicado pela pesquisa de Lal et al., (1995) e Krishnamurthy e Ávila, (1999), onde eles evidenciaram que em climas tropicais os solos sob vegetação florestal exibem maiores potenciais de dreno de $\mathrm{C}$, em função do uso do solo para outros fins. Conforme Kuhnen (2013) o nitrogênio é essencial para analisar estudos referente a matéria orgânica do solo. Ele é encontrado na forma orgânica, contudo a biota do solo os transforma em substâncias mais simples.

Teores muito baixos de nutrientes não são atrativos para a biota do solo, mesmo a relação $\mathrm{C} / \mathrm{N}$ sendo alta, o eucalipto apresentou a maior razão $\mathrm{C} / \mathrm{N}$, ou seja, possui folhas mais coriáceas, de menores teores de nutrientes e lignina, não se decompondo facilmente, o seu decaimento é lento permanecendo no solo por vários anos, explicando as baixas taxas de decomposição encontradas nesse trabalho. 


\section{CONCLUSÃO}

A biomassa decomposta da serapilheira foliar teve um padrão similar nas duas áreas. No entanto, a decomposição do eucalipto foi maior que o cerrado em partes.

A precipitação e a temperatura influenciaram na perda de massa da serapilheira foliar.

A relação $\mathrm{C} / \mathrm{N}$ foi alta nas duas vegetações, no entanto, o eucalipto apresentou maior taxa de relação $\mathrm{C} / \mathrm{N}$, menor velocidade de decomposição. 


\section{REFERÊNCIAS BIBLIOGRÁFICAS}

ABER, J.D. \& MELILLO, J.M. (1980) Litter decomposition: measuring relative contributions of organic matter and nitrogen to forest soils. Canadian Journal of Botany, Ottawa, v. 58, p.416-421.

ADAMS, M. A.; ATTIWILL, P.M. Nutrient cycling an nitrogen mineralization in eucalypt forests south-easthern Australia. I. Nutrient Cycling and nitrogen turnover. Plant and Soil, v. 92, p.319339, 1986.

ALVARENGA, A. A. et al. Desenvolvimento de mudas de Guarea [Guarea guidonea (L.) Sleumer], Daphene, v. 8, n. 3, p. 22-26, 1998.

ANDERSON, J. D.; INGRAM, J. S. I. Tropical soil biology and fertility: A handbook of methods. 2. ed. Wallingford: CAB International, p. 171, 1996.

ANDRADE, A, G. Ciclagem de nutrientes e arquitetura radicular de leguminosas arbóreas de interesse para a vegetação de solos degradados e estabilização de encostas. 1997.182 f. Tese (Doutorado) - Instituto de Agronomia, Universidade Federal Rural do Rio de Janeiro, Seropédica.

ARATO, H. D.; MARTINS, S. V.; FERRARI, S. H. S. Produção e decomposição de serapilheira em um sistema agroflorestal implantado para recuperação de área degradada em Viçosa-MG. Árvore, Viçosa, v. 27, n. 5, p. 715-721, out. 2003.

BALIEIRO FC, OLIVEIRA WC, PEREIRA MG, ANJOS LHC, PICCOLO MC, JACCOUD CF. Fertilidade e carbono do solo e uso da água pelo eucalipto numa topossequência em Seropédica, RJ. Revista Árvore .2008.

BALIEIRO, F.D.C., ALVES, B.J.R., PEREIRA, M. G., FARIA, S.M.D., FRANCO, A. A.; CAMPELLO, E. F. C. Biological nitrogen fixation and nutrient release from litter of the guachapele leguminous tree under pure and mixed plantation with eucalyptus. Cerne, 14 (3), 185-193, 2008.

BARLOW, A. J. et al. Litter fall and decomposition in primary, secondary and plantation forests in the Brazilian Amazon. Forest Ecology and Management, v. 247, n. 1-3, p. 91-97, Aug. 2007. 
BARRETO, P. A. B.; GAMA-RODRIGUES. E. F.; GAMA-RODRIGUES, A. C.; BARROS, N. F.; FONSECA, S. Atividade, carbono e nitrogênio da biomassa microbiana em plantações de eucalipto, em uma seqüência de idades. Revista Brasileira de Ciência do Solo, Viçosa, v. 32, n. 2, p. 611-619, 2008

BASTOS, L. A E FERREIRA, I. M. Composições Fitofisionômicas do Bioma Cerrado: Estudo sobre o subsistema de Vereda. Espaço em Revista, UFG-CAC, v. 12, n. 1, p. 97-108, 2010.

BEARE, M. H., PARMELEE, R. W., HENDRIX, P. F. \& GHENG, W. 1992. Microbial and faunal interactions and effects on litter nitrogen and decomposition agroecosystems. Ecological Monographs, 62 (4): 569-591.

BERG, B.; MCCLAUGHERTY, C. Plant litter: decomposition, humus formation, carbon sequestration. Berlin: Springer, 2003. 286p.

BOCOCK, K.L.; GILBERT, O.J.W. The disappea-rance of litter under different woodland conditions. Plant and Soil, v.9, n.2, p.179-185, 1957.

BROWN, S.; LUGO, A. E. Effects of forest clearing and succession on the carbon and nitrogen content of soils in Puerto Rico and US Virgin Islands. Plant and Soil, The Hague, v. 124, p. 5364, 1990.

CERRI, C.C.; BERNOUX, M.; CARVALHO, M.C.S.C. \& VOLKOFF, B. Primeiro inventário brasileiro de emissões antrópicas de gases de efeito estufa: Emissões e remoções de dióxido de carbono pelos solos por mudanças de uso da terra e calagem. Brasília, Ministério da Ciência e Tecnologia, 2001. 41p.

CORREAA NETO TA, ANJOS LHC, PEREIRA MG, AMORIM HB, JACCOUD CFS. Atributos edafoambientais e parâmetros dendrométricos de plantios de eucalipto em uma topossequência no campus da UFRRJ, Seropédica-RJ. Ciência Florestal. 2007.

CORREIA, M.E.F.; ANDRADE, A.G. Formação de serapilheira e ciclagem de nutrientes. In: (Eds.). SANTOS, G.A.; CAMARGO, F.A.O. Fundamentos da Matéria Orgânica do Solo: ecossistemas tropicais e subtropicais. Porto Alegre: Genesis, 1999. p.197-226.

COSTA JUNIOR, D. P. da; BERNINI, F. S. Cerrado: Beleza Oculta. Campinas: Engecrol, 2008. 178 p. 
COSTA, G. S.; GAMA-RODRIGUES, A. C.; CUNHA, G. M. Decomposição e liberação de nutrientes da serapilheira foliar em povoamentos de Eucalyptus grandis no Norte Fluminense. Revista Árvore, v. 29, n. 4, p. 563-570, 2005

COÛTEAUX, M. M.; BOTTNER, P.; Berg. B. Litter decomposition, climate and litter quality. Tree, v. 10, n.2, p.63-66, 1995.

DIAS, B.F. de S. Cerrados: uma caracterização. In: DIAS, B. F. de S (Coord.). Alternativas de desenvolvimento dos cerrados: manejo e conservação dos recursos naturais renováveis. Brasília: Fundação Pró-Natureza, 1992. p. 11-25.

EIRA, A. F. Influência da cobertura morta na biologia do solo. 1995. In: DISPERATI, A. A.; FERREIRA, C. A.; MACHADO, C.; GONÇALVES, J. L. M. \& SOARES, R. V. (Orgs.). Seminário sobre cultivo mínimo do solo em florestas, 1., Curitiba, p.16-33.

EMBRAPA. Sistema Brasileiro de Classificação de Solos. Brasília: Embrapa, 2013.p. 353.

FAL - $\quad$ Fazenda Água Limpa . Disponível em http://www.fav.unb.br/laboratorios/laboratorio-de-agroclimatologia. Acesso em: $10 \mathrm{de}$ novembro de 2017.

FALLOON, P.; JONES, C.D.; CERRI, C.E.; AL-ADAMAT, R.; KAMONI, P.; BHATTACHARYYA, T.; EASTER, M.; PAUSTIAN, K.; KILLIAN, K.; COLEMAN, K. \& MILNE, E. Climate change and its impact on soil and vegetation carbon storage in Kenya, Jordan, India and Brazil. Agric. Ecosyst. Environ., 122:114-124, 2007.

FARIA, G. E., BARROS, N. F., NOVAIS, R. F.; SILVA, I. R.; NEVES, J. C. L. Carbono orgânico total e frações da matéria orgânica do solo em diferentes distâncias do tronco de eucalipto. Scientia Forestalis, Piracicaba. v. 36, n. 80, p. 265-277, 2008.

FERREIRA, M. Melhoramento e a silvicultura intensiva clonal. IPEF, Piracicaba, $n$. 45. p. 22-30, 1992.

GAMA-RODRIGUES, A.C.; BARROS, N.F. Ciclagem de nutrientes em floresta natural e em plantios de eucalipto e de dandá no sudeste da Bahia, Brasil. Revista Árvore, v. 26, n.2, p.193-207, 2002.

GATTO, A. et al. Estoques de Carbono no solo e na biomassa em plantações de Eucalipto. Revista Brasileira de Ciência do Solo, v. 34, n. 4, p. 1069-1079, 2010. 
GONÇALVES, J.L.M.; STAPE, J.L. (Ed.) Conservação e cultivo de solos para plantações florestais. Piracicaba: IPEF, 2002. P.49-124.

GUO LB, SIMS REH. Eucalypt litter decomposition and nutrient release under a short rotation forest regime and effluent irrigation treatments in New Zealand I. External effects. Soil Biology und Biochemistry 2001; 33(10): 1381-1388.

HEAL, O.W.; ANDERSON J.M.; SWIFT, M.J. Plant litter quality and decomposition: an historical overview. P 3-30. In: CADISH, G.; GILLER, K.E. (Eds.). Driven by Nature: plant litter quality and decomposition. Walingford: CAB International, 1997. $409 \mathrm{p}$.

HAAG, H. P. 1987. A nutrição mineral e o ecossistema. In: CASTRO, P. R. C., FERREIRA, S. O., YAMADA, T. (Ed.) Ecofisiologia da produção agrícola. Piracicaba: Associação Brasileira para Pesquisa da Potassa e do Fosfato. p. 49-52.

HAMMER, O.; HARPER, D. A. T.; RYAN, P. D. PAST: Paleontological statistics software package for education and data analysis. Palaeontologia Electronica, v. 4, n. 1, p. 1-9, 2001.

HEAL, O.W.; ANDERSON J.M.; SWIFT, M.J. Plant litter quality and decomposition: an historical overview. P 3-30. In: CADISH, G.; GILLER, K.E. (Eds.). Driven by Nature: plant litter quality and decomposition. Walingford: CAB International, 1997.

IBÁ - Industria Brasileira de Árvores. Relatório Anual Ibá 2016. Disponível em: < http://iba.org/images/shared/Biblioteca/IBA_RelatorioAnual2016_.pdf>. Acesso em: 14 de julho de 2016.

KÖNIG, F. G. et al. Avaliação da sazonalidade da produção de serrapilheira numa floresta estacional decidual no município de Santa Maria-RS. Árvore, Viçosa, v. 26, n. 4, p. 429-435, ju./ago. 2002409 p

KRISHNAMURTHY, L. \& AVILA, M. Agroforesteria básica. México, Red. de Formación Ambiental para América Latina y el Caribe. Programa de las Naciones Unidas para el Médio Ambiente, 1999. p.29-36.

KUHNEN, F. 2013. Mineralização de nitrogênio de solos e de resíduo orgânico em laboratório e em campo. Tese Doutorado. Universidade Estadual Paulista, JaboticabalSP. 64p. 
LAL, R. Forest soils and carbon sequestration. For. Ecol. Manag., 220:242-258, 2005.

LAL, R.; KIMBLE, J. \& STEWART, B.A. World soils as a source or sink for radiatively-active gases. In: LAL, R.; KIMBLE, J.; LEVINE, E. \& STEWART, B.A., eds. Soil management and greenhouse effect. Boca Raton, CRC Lewis Publishers, 1995. p.1-7.

LAL, R. Soil carbon sequestration impacts on global climate change and food security. Science, Washington, v. 304, p. 1623-1627, 2004.

LARCHER, W. Ecofisiologia vegetal. São Paulo: EPU, 1986. 319 p.

LAVELLE, P.; BLANCHART, E.; MARTIN, A.; MARTIN, S.; SPAIN, A.; TOUTAN, F.; BAROIS, I.; SCHAEFER, R. A hierarchical model for decomposition in terrestrial ecosystems: Application to soils of the humid tropics, Biotropica, v. 25, p.130-150, 1993.

LOUZADA, J.N.C. et al. Litter decomposition in semidecidous forest and Eucalyptus spp. crop in Brazil: a comparison. Forest Ecology and Management, v. 94, p.3136,1997 .

LUIZÃO, F. J. Produção e decomposição de literia em floresta de terra firme da Amazônia Central. Aspectos químicos e biológicos da lixiviação e remoção dos nutrientes da literia. 1982. 107 f. Dissertação (Mestrado) - INPA/Fundação Universidade Federal do Amazonas, Manaus.

MARIMON-JUNIOR, B.H. \& HARIDASAN, M. Comparação da vegetação arbórea e características edáficas de um cerradão e um cerrado sensu stricto em áreas adjacentes sobre solo distrófico no leste de Mato Grosso, Brasil. Acta Botanica Brasilica, São Paulo, v.19: p.913-926, 2005.

MARTINS, S. V. Recuperação de áreas degradadas: ações em áreas de preservação permanente, voçorocas, taludes rodoviários e de mineração. Viçosa: Aprenda Fácil, 2009. $270 \mathrm{p}$

MELILLO, J. M., ABER, J. D. \& MURATORE, J. F. 1982. Nitrogen and lignin control of hardwood leaf litter decomposition dynamics. Ecology, 63: 621-626

MENDONÇA, R. C.; FELFI LI, J. M.; WALTER, B. M. T.; SILVA JÚNIOR, M. C.; REZENDE, A. V.; FILGUEIRAS, T. S.; NOGUEIRA, P. E.; FAGG C. W. Flora 
vascular do Bioma Cerrado: checklist com 12.356 espécies. In: SANO, S. M.; ALMEIDA, S. P.; RIBEIRO, J. F. (Eds.). Cerrado: ecologia e flora Brasília. Embrapa Informação Tecnológica: Planaltina, 2008. p. 422-442.

MITTERMEIER, R.A., GIL, R.P., HOFFMAN, M., PILGRIM, J., BROOKS, T., MITTERMEIER, C.G., LAMOREUX, J. \& FONSECA, G.A.B. . Hotspots revisited: earth's biologically richest and most endangered terrestrial ecoregions, 2 . ed. University of Chicago Press, Boston. 2005.

MONTEIRO, M. T.; GAMA-RODRIGUES, E. F. Carbono, nitrogênio e atividade da biomassa microbiana em diferentes estruturas de serapilheira de uma floresta natural. Revista Brasileira de Ciência do Solo, Viçosa, v. 28, n. 5, p. 819-826, 2004.

MOORHEAD, D.L.; CURRIE, W.S.; RASTTETTER, E.B.; PARTON, W.J.; HARMON, M.E. Climate and litter quality controls on decomposition: na analysis of modeling approaches. Global Biogeochemical Cycles, Washington, v. 13, p. 575-589, 1999.

MOREIRA, F. M. de S. \& SIQUEIRA, J. O. 2006. Microbiologia e Bioquímica do Solo. 2.ed. atualizada e ampliada. Lavras: UFLA. 729 p. NUNES, F. P. \& PINTO, M. T. C. 2012. Decomposição do folhedo em reflorestamento ciliar na bacia hidrográfica do rio São Francisco, Minas Gerais. Cerne, 18 (3): 423-431

MOREIRA, F.M.S.; SIQUEIRA, J.O.2006. Microbiologia e bioquímica do solo. UFLA,2 ed., Mato Grosso do Sul, 74 p.

MOTA, F.C.M (2017). Biomassa, fluxos de Carbono e energia em área de Cerrado sentido restrito e plantio de Eucalipto no Distrito Federal. Tese de Doutorado em Ciências Florestais. Publicação PPG/EFL. TD. 078/2017, Programa de Pós-graduação em Ciências Florestais, Universidade de Brasília, Brasília-DF, 157 p.

ODUM, E. P. Ecologia. Rio de Janeiro: Guanabara, 1986, 434 p.

OLIVEIRA FILHO, A. T.; RATTER, J. A. Vegetation Physiognomies and Woody Flora of the Cerrado Biome. In: OLIVEIRA, P. S.; MARQUIS, R. J. (Eds.). The Cerrados of Brazil: ecology and natural history of a neotropical savanna. New York: Columbia University Press, 2002. p. 91-120. 
OLSON, J.S. Energy storage and the balance of producers and decomposers in ecological systems. Ecology, Washington, v. 44, p.322-332, 1963.

PAIVA, A. A.; REZENDE, A. V.; PEREIRA, R. S. Estoque de Carbono em Cerrado sentido restrito do Distrito Federal. Revista Árvore, v. 35, n.13, p. 527-538, 2011.

PANDEY, R. R. et al. Litterfall, litter decomposition and nutrient dynamics in a subtropical natural oak forest and managed plantation in northeastern India. Forest Ecology and Management, v. 240, n. 1-3, p. 96-104, Mar. 2007.

PEGADO, C. M. A.; BARBOSA, L. J. N.; MENDES, J. E. M. F.; SOUTO, P. C. \& SOUTO, J. S. 2008. Decomposição superficial e subsuperficial de folhas de fava (Phaseolus lunatus L.) na região do Brejo da Paraiba, Brasil. Caatinga, 21 (1): 218-223

PEREIRA, J. C. D; STURION, J. A; HIGA, A. R. HIGA, R. C. V. SHIMIZU, J. Y. Características da madeira de algumas espécies de eucalipto plantadas no Brasil. Colombo: Embrapa Florestas, 113p. (Embrapa Florestas. Documentos, 38. 2000).

POGGIANI, F. et al. Indicadores de sustentabilidade das plantações florestais. Série Técnica IPEF, v. 12, n. 31, p. 33 - 44, abr., 1998.

REIS, G. G. et al. Crescimento de raízes e da parte aérea de clones de híbridos de Eucalyptus grandis x Eucalyptus urophylla e de Eucalyptus camaldulensis x Eucalyptus spp submetidos a dois regimes de irrigação no campo. Revista Árvore, v. 30, n. 6, p. 921931, 2006.

RIBEIRO, J.F.; DIAS, T. Diversidade e conservação da vegetação e da flora. In: Ministério do Meio Ambiente. Biodiversidade do Cerrado e Pantanal: áreas e ações prioritárias para conservação. Brasília: Ministério do Meio Ambiente, 2007. p. 21-46.

RIBEIRO, J. F.; WALTER, B. M. T. Fitofisionomias do bioma Cerrado. In: SANO, S. M.; ALMEIDA, S. P. (Eds.). Cerrado: ambiente e flora. Planaltina: Embrapa CPAC, 1998. p. 89-166.

RIBEIRO, J. F.; WALTER, B. M. T. As Principais Fitofisionomias do Bioma Cerrado. In: SANO, S. M.; ALMEIDA, S. P.; RIBEIRO, J. F. (Eds.). Cerrado: ecologia e flora. Brasília: Embrapa Informação Tecnológica, 2008. p. 151-212. 
RODIGHERI, H. R. Rentabilidade econômica comparativa entre plantios florestais e sistemas agroflorestais com erva-mate, eucalipto e pinus e as culturas do feijão, milho, soja e trigo. Colombo: EMBRAPA-CNPF, 1997. 36p. (Circular técnica, n.26).

RYAN, M. G. et al. Factores controlling Eucalyptus productivity: how resource availability and stand structure alter production an carbon allocation. Forest Ecology and Management, v. 259, p. $1695-1703,2010$.

SANO, E. E. et al. Mapeamento do uso do solo e cobertura vegetal - bioma Cerrado: ano base 2002. Brasília: MMA/SBF, 2010. p. 96.

SANTANA, R.C.; BARROS, N.F.; NOVAIS, R.F.; LEITE, H.G. \& COMERFORD, N.B. Alocação de nutrientes em plantios de eucalipto no Brasil. R. Bras. Ci. Solo, $32: 2723-2733,200$

SANKARAN KV. Decomposition of leaf litter of albizia (Paraserianthes falcataria), eucalypt (Eucalyptus tereticornis) and teak (Tectona grandis) in Kerala, India. Forest Ecology and Management 1993; 56 (1-4): 225-242.

SANTAROSA, E.; PENTEADO JUNIOR, J. F.; GOULART, I. C. G. dos R. Transferência de tecnologia florestal: cultivo de eucalipto em propriedades rurais: diversificação da produção e renda. Embrapa Florestas. Brasília, v. 1, 138p, 2014.

SARIYILDIZ, T.; ANDERSON, J.M. Decomposition of sun and shade leaves from three deciduous tree species, as affected by their chemical composition. Biology and Fertility of Soils, Berlin, v. 37, n. 3, p. 137-146, 2003.

SCANAVACA JUNIOR, Laerte; GARCIA, José Nivaldo. Rendimento em madeira serrada de Eucalyptus urophylla. 2003.

SCORIZA, R.N.; PEREIRA, M.G.; PEREIRA, G.H.A.; MACHADO, D.L.; SILVA, E.M.R. Métodos para coleta e análise de serrapilheira aplicados à ciclagem de nutrientes. Floresta \& Ambiente, Rio de Janeiro, v.2, n.2, p.1-18, 2012.

SHUMACHER, M.V. Aspectos da ciclagem de nutrientes e do microclima em talhões de Eucalyptus camaldulensis Dehnh, Eucalyptus grandis Hill ex Maiden e Eucalyptus torelliana F. Muell. 1992. 104 f. Dissertação (Mestrado) - Escola Superior da Agricultura Luiz de Queiroz, Universidade de São Paulo, Piracicaba. 
SHUMACHER, M.V. Produção de serapilheira em uma floresta de Araucaria angustifolia (Bertol.) Kuntze no município de Pinhal Grande-RS. Revista Árvore, Viçosa, v. 28, n.1, p. 29-37, 2004.

SILVA, F. A. M.; ASSAD, E. D.; EVANGELISTA, B. A. Caracterização Climática do Bioma Cerrado. In: SANO, S. M.; ALMEIDA, S. P.; RIBEIRO, J. F. (Eds.). Cerrado: ecologia e flora. Brasília: Embrapa Informação Tecnológica, 2008. p. 69-88.

SILVA, I.R. \& MENDONÇA, E.S. Matéria orgânica do solo. In: NOVAIS, R.F.; ALVAREZ V., V.H.; BARROS, N.F.; FONTES, R.L.F.; CANTARUTTI, R.B. \& NEVES, J.C.L. eds. Fertilidade do solo. Viçosa, MG, Sociedade Brasileira de Ciência do Solo, 2007. p.275-374.

SILVA, J.M.C.; SANTOS, M.P.D. A importância relativa dos processos biogeográficos na formação da avifauna do Cerrado e de outros biomas brasileiros. In: SCARIOT, AD.; SOUSA-SILVA, J.C.; FELFILI, J.M. (Org.). Cerrado: ecologia, biodiversidade e conservação. Brasília: Ministério do Meio Ambiente, 2005. p. 219-233.

SKORUPA, A. L. A. Acumulação e decomposição de serapilheira em povoamento de eucalipto, na Região do Baixo do Rio Doce-MG. 2001. 64f. Dissertação (Mestrado em Solos e Nutrição de Plantas) Universidade Federal de Viçosa, Viçosa, MG, 2001.

SLEUTEL, S.; NEVES, S. de; HOFMAN, G. Estimates of carbon stock changes in Belgian cropland. Soil Use and Management, Oxford, v. 19, n. 2, p. 166-171, 2006.

SMITH, P. Land use change and soil organic carbon dynamics. Nutr. Cycling Agroecosyst., 81:169-178, 2008.

SMITH, V. C.; BRADFORD, M. A. Litter quality impacts on grassland litter decomposition are differently dependent on soil fauna across time. Applied Soil Ecology, v. 24, p.197-203, 2003.

SONGWE, N.C.; OKALI, D.U.U.; FASEHUN, F.E. Litter decomposition and nutriente release in a tropical rainforest, Sourthern Bakundu Forest Reserve, Cameroon. Journal of Tropical Ecology, v. 11, p. 333-350, 1995.

STEVENSON, F.J. Humus chemistry: genesis, composition, reactions. 2.ed. New York: J. Wiley, 1994. 496p. 
TAIZ, L.; ZEIGER, E. Fisiologia do estresse. In: Santarém, E. R.; Mariath, J. E. de A.; Astarita, L. V.; Dillenburg, L. R.; Rosa, L. M. G. \& Oliveira, P. L. de. (Trad.). Fisiologia vegetal. $3^{\mathrm{a}}$ ed. Artmed Editora S.A., Porto Alegre, Brasil, p.613-641. 2004.

TAYLOR, B. R., PARKINSON, D. \& PARSONS, W. F. J. 1989. Nitrogen and lignin content as predictors of litter decay rates: a microcosm test. Ecology, 70: 97-104.

TEIXEIRA, M. B.; LOSS, A.; PEREIRA, M. G. \& PIMENTEL, C. 2012. Decomposição e ciclagem de nutrientes dos resíduos de quatro plantas de cobertura do solo. Idesia, 30 (1): 55-64.

TEIXEIRA, L.B., OLIVEIRA, R.F. MARTINS, P.F. Ciclagem de nutrientes através da literia em floresta, capoeira e consórcios com plantas perenes. Revista Ciências Agrárias, v. 36, p. 91-99, 2001.

VIEIRA, J. A. G.; TEIXEIRA, M. B.; LOSS, A.; LIMA, E. ZONTA, E. Produção de Serapilheira e Retorno de Nutrientes ao Solo pela Espécie Eucalyptus urograndis. Revista Brasileira de Agroecologia, v. 4, n. 2, p. 40-43, 2009.

WARDLE, D. A. \& LAVELLE, P. 1997. Linkages between soil biota, plant litter quality and decomposition. In: CADISCH, G. \& GILLER, K.E. (Eds.). Driven by nature: plant litter quality and decomposition. Wallingford: CAB International. p. 107-123.

ZAR, J. H. Análise Biostatistical. 5.ed. New Jersey: Prentice Hall, 2010, 944 p. 